Article

\title{
Spatiotemporal Variability of Mesoscale Eddies in the Indonesian Seas
}

\author{
Zhanjiu Hao ${ }^{1,2}$, Zhenhua Xu ${ }^{1,3,4,5, * \mathbb{D}}$, Ming Feng ${ }^{6,7}$, Qun Li ${ }^{8}$ and Baoshu Yin ${ }^{1,2,3,4,5}$ \\ 1 CAS Key Laboratory of Ocean Circulation and Waves, Institute of Oceanology, Chinese Academy of Sciences, \\ Qingdao 266071, China; haozhanjiu@qdio.ac.cn (Z.H.); bsyin@qdio.ac.cn (B.Y.) \\ 2 University of Chinese Academy of Sciences, Beijing 100049, China \\ 3 Pilot National Laboratory for Marine Science and Technology, Qingdao 266237, China \\ 4 Center for Ocean Mega-Science, Chinese Academy of Sciences, Qingdao 266071, China \\ 5 CAS Engineering Laboratory for Marine Ranching, Institute of Oceanology, Chinese Academy of Sciences, \\ Qingdao 266071, China \\ 6 CSIRO Oceans and Atmosphere, Indian Ocean Marine Research Centre, Crawley, WA 6009, Australia; \\ ming.feng@csiro.au \\ 7 Centre for Southern Hemisphere Oceans Research, Hobart, TAS 7000, Australia \\ 8 Polar Research Institute of China, Shanghai 200136, China; liqun@pric.org.cn \\ * Correspondence: xuzhenhua@qdio.ac.cn
}

Citation: Hao, Z.; Xu, Z.; Feng, M.; Li, Q.; Yin, B. Spatiotemporal Variability of Mesoscale Eddies in the Indonesian Seas. Remote Sens. 2021, 13, 1017. https://doi.org/10.3390/ rs13051017

Academic Editors: Chung-Ru Ho, Antony K. Liu and Xiaofeng Li

Received: 25 January 2021

Accepted: 4 March 2021

Published: 8 March 2021

Publisher's Note: MDPI stays neutral with regard to jurisdictional claims in published maps and institutional affiliations.

Copyright: (c) 2021 by the authors. Licensee MDPI, Basel, Switzerland. This article is an open access article distributed under the terms and conditions of the Creative Commons Attribution (CC BY) license (https:/ / creativecommons.org/licenses/by/ $4.0 /)$.

\begin{abstract}
Mesoscale eddies are ubiquitous in the world ocean and well researched both globally and regionally, while their properties and distributions across the whole Indonesian Seas are not yet fully understood. This study investigates for the first time the spatiotemporal variations and generation mechanisms of mesoscale eddies across the whole Indonesian Seas. Eddies are detected from altimetry sea level anomalies by an automatic identification algorithm. The Sulu Sea, Sulawesi Sea, Maluku Sea and Banda Sea are the main eddy generation regions. More than $80 \%$ of eddies are short-lived with a lifetime below 30 days. The properties of eddies exhibit high spatial inhomogeneity, with the typical amplitudes and radiuses of $2-6 \mathrm{~cm}$ and $50-160 \mathrm{~km}$, respectively. The most energetic eddies are observed in the Sulawesi Sea and Seram Sea. Eddies feature different seasonal cycles between anticyclonic and cyclonic eddies in each basin, especially given that the average latitude of the eddy centroid has inverse seasonal variations. About $48 \%$ of eddies in the Sulawesi Sea are highly nonlinear, which is the case for less than $30 \%$ in the Sulu Sea and Banda Sea. Instability analysis is performed using high-resolution model outputs from Bluelink Reanalysis to assess mechanisms of eddy generation. Barotropic instability of the mean flow dominates eddy generation in the Sulu Sea and Sulawesi Sea, while baroclinic instability is slightly more in the Maluku Sea and Banda Sea.
\end{abstract}

Keywords: mesoscale eddies; the Indonesian Seas; sea level anomaly; nonlinearity; barotropic instability; baroclinic instability

\section{Introduction}

The progress of numerical models and remote sensing techniques, especially satellite altimeter, in the past few decades has greatly advanced our understanding of mesoscale eddies in the ocean, which contain most of the oceanic kinematic energy [1]. Mesoscale eddies have characteristic spatial and temporal scales ranging from tens to hundreds of kilometers and from several days to years, respectively [2]. Both cyclonic (CE) and anticyclonic (AE) eddies are ubiquitous in the ocean [1], serving as a key bridge of energy cascade between large-scale and sub-mesoscale oceanic dynamics [3-5]. Because of their nonlinearity, mesoscale eddies play a vital role in the transport of momentum, mass, heat and biogeochemical properties and further impact tracer budgets and primary production $[2,6]$.

Most existing analyses focused on several hot spots, such as strong meandering currents, the eastern boundary upwelling system and marginal seas [7-13]. However, eddies at low latitudes, where meridional heat transport was found to be significant, are 
not well studied [14]. To our knowledge, the sparse temporal resolution of altimeter data over the past few decades restricted researchers to only focusing on the long-lived eddies mainly populating middle to high latitudes [15]. In addition, numerical models may not reproduce realistic positions and properties of eddies because of their highly variable nature [16]. Fortunately, the daily-resolution merged sea surface height (SSH) products have been available in recent years, which allow us to study short-lived eddies with a lifetime of several days $[15,17]$. Hence, more and more investigators have been addressing the spatiotemporal variations of eddies in low latitudes, such as the Tropical Atlantic Ocean and Peruvian oceanic region $[18,19]$. Based on daily-resolution SSH products, Chen and Han [15] find that an apparent short-lived eddy zonal belt populates the tropical ocean, including the Indo-Pacific warm pool.

The Indonesian Seas, with numerous narrow channels connecting seas of different sizes and depths, provide the sole tropical pathway from the Pacific to the Indian Ocean known as the Indonesian Throughflow (ITF) [20,21]. Extensive studies based on the moorings and numerical models revealed the upper-ocean circulation in this area as schematically shown in Figure 1. In the west route of the ITF, the Mindanao Current (MC) divides into three branches south of the Mindanao Island: one flows eastward into the North Equatorial Countercurrent (NECC); another one flows southwestward firstly and then turns back into the Pacific; and the thirds intrudes into the Sulawesi Sea [22,23]. For the intrusion of $\mathrm{MC}$, a portion turns eastward and flows back into the Pacific along the pathway north of the Sulawesi Island; and the rest flows southward through Makassar Strait, known as the Makassar Strait Throughflow (MST), then flows into the Flores Sea and Banda Sea [24]. Meanwhile, the east route of the ITF is from the Maluku Sea and Halmahera Sea to the Seram Sea then into the Banda Sea $[23,25]$. Additionally, small amounts of water from the South China Sea (SCS) are carried into the Sulu Sea and Java Sea via the Mindoro Strait and Karimata Strait (KS), respectively [26,27]. The ITF waters eventually exit the Indonesian Seas via the narrow straits of Lesser Sunda Islands and the Timor Passage $[20,21]$. As one of the significant features in the ocean circulation, mesoscale eddies can exchange energy with background currents through eddy-mean flow interaction [3-5]. Although we presently have a more advanced understanding of the ITF and its intraseasonal-to-decadal variability [20,21], eddies in the Indonesian Seas, significantly contributing to the intraseasonal variation of ITF transport, are poorly understood [28,29].

Mesoscale eddies in the Indonesian Seas exhibit multiscale temporal variations associated with the ITF. For the intraseasonal scale, a 50-day oscillation of horizontal velocity was observed from moorings at the entrance of Sulawesi Sea [30]. Based on a 1.5-layer reduced-gravity model, Qiu et al. [28] pointed out that this intense 50-day oscillation in the Sulawesi basin is a result of baroclinic Rossby wave resonance. The 50-day oscillation signals also exhibit intense interannual variability modulated by active eddy shedding, and enhanced 50-day oscillation can freshen the upper-ocean water mass in the Sulawesi Sea and Makassar Strait [31]. Through an ocean general circulation model (OGCM), three eddies in the Flores Sea were simulated in austral summer when ITF transport is low, and these eddies vary synchronously at an interannual scale, thus named as "Lombok Eddy Train" [32]. In terms of the seasonal cycle, the variation of eddy kinematic energy (EKE) in the Sulawesi Sea has different periods at different depths, and the annual and semi-annual peaks are in the 0-100 m layer and the 100-300 m layer, respectively [33]. In the Sulu Sea, AEs and CEs display an opposite seasonal variability, with more and larger AEs in boreal winter and CEs in boreal summer [34]. However, a comprehensive description of properties, seasonal variability and generation mechanism for eddies in the Indonesian Seas is still lacking.

This study provides a comprehensive statistical description of the spatiotemporal variability of eddies in the Indonesian Seas using long term altimeter data. The mechanisms of eddy generation are investigated through instability analysis based on highresolution model outputs. We believe that an overall presentation of mesoscale eddies in 
the Indonesian Seas will not only improve local ocean forecasts but also facilitate a better understanding of their roles in climate and ecosystems. The remainder of this paper is organized as follows: Section 2 describes the details of data and methods used in this study. Section 3 provides a statistical description of eddy properties. The mechanisms of eddy generation are discussed in Section 4. Section 5 provides a summary of the results.

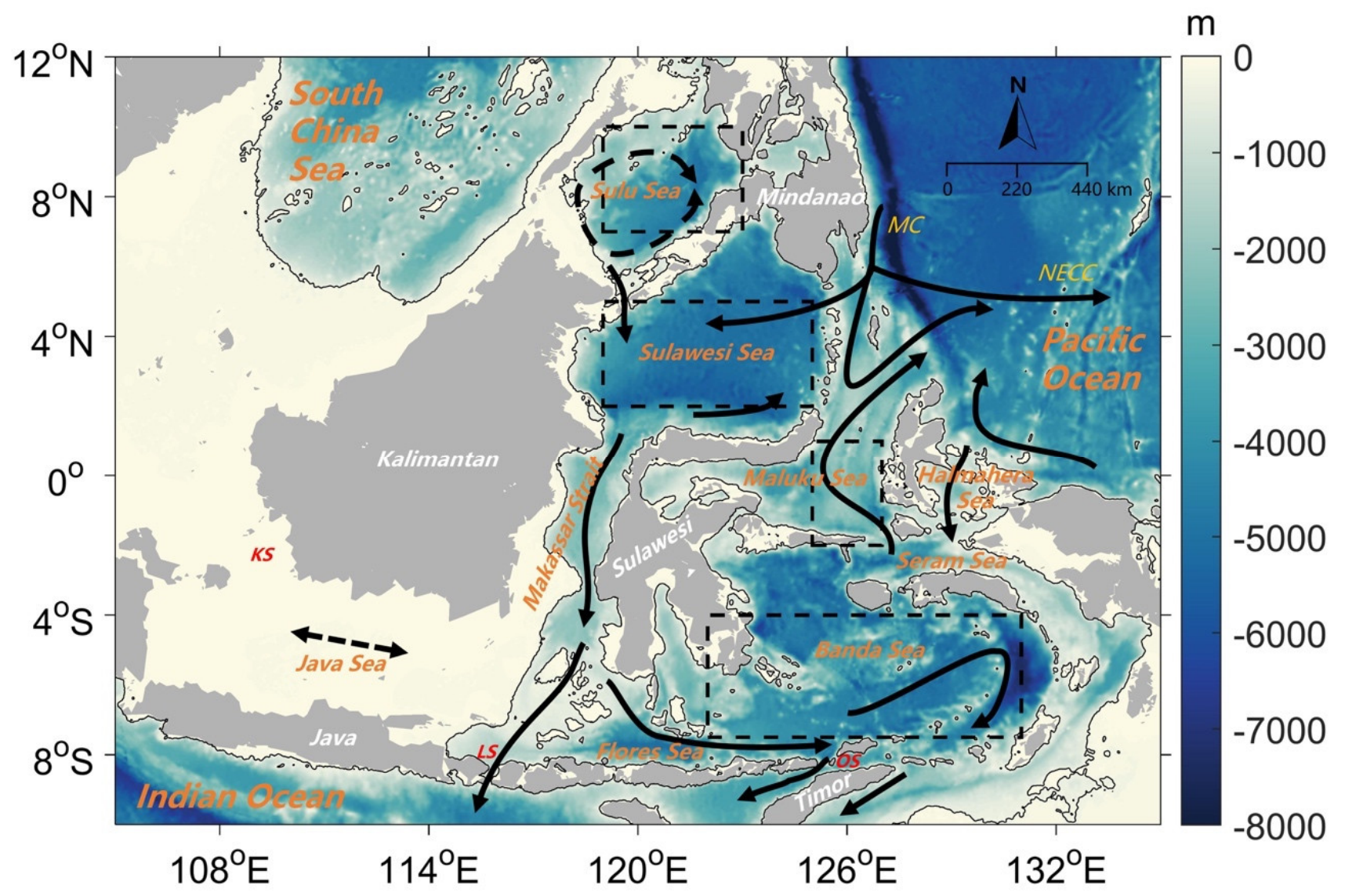

Figure 1. Schematic of the upper-ocean circulation in the Indonesian Seas. Color shading is the bathymetry from ETOPO1. The solid line is the $200 \mathrm{~m}$ isobath. KS, LS and OS represent the Karimata Strait, Lombok Strait and Ombai Strait, respectively. MC and NECC represent the Mindanao Current and North Equatorial Countercurrent, respectively. Four dashed boxes are the Sulu Box, Sulawesi Box, Maluku Box and Banda Box from north to south, respectively.

\section{Materials and Methods}

\subsection{Altimeter Data}

The delayed-time altimeter data used in this study is a Ssalto/Ducas gridded product of SSH, sea level anomaly (SLA) and geostrophic current from January 1992 to December 2019 provided by Archiving, Validation, and Interpolation of Satellite Oceanographic (AVISO) data and distributed by the Copernicus Marine Environment Monitoring Service (CMEMS). This product has been widely used to detect mesoscale eddies globally $[17,35]$ and regionally $[12,19,34,36]$. The SLA product was constructed by merging multi-mission satellites since 1992 optimally interpolated onto $0.25^{\circ} \times 0.25^{\circ}$ grid with a daily resolution. The geostrophic velocity was computed by the Lagerloef methodology [37] introducing the $\beta$-plane approximation in the equatorial band $\left(5^{\circ} \mathrm{S} \sim 5^{\circ} \mathrm{N}\right)$, and by the 9-point stencil width ("stencil width" means the number of grid points utilized to estimate the finite difference approximation to the derivative on a grid) methodology outside the equatorial band [38]. Following Chelton et al. [2], the SLA fields are therefore spatially high-pass filtered with half-power filter cutoffs of $20^{\circ}$ longitude $\times 10^{\circ}$ latitude to remove steric heating and cooling effects, as well as other large-scale variability of SLA. The readers should be reminded that altimeter data become less accurate over the shelf area due to some aliases from the 
tides, coastal wave signals and sea-land transition [39]. Thus, the altimeter data in areas shallower than $200 \mathrm{~m}$ are masked in this study.

\subsection{Bluelink ReANalysis}

To study the mechanisms of eddy generation, we use the latest model outputs from Bluelink ReANalysis (BRAN, version of 3p5) to perform an instability analysis. The BRAN model is a multi-year integration of Ocean Forecasting Australian Model (OFAM) assimilating observations of SLA and SST from satellite, sea level data from tide gauges and in situ temperature and salinity profiles by using Bluelink Ocean Data Assimilation System (BODAS) [40]. This model domain covers the Indonesian Seas and surrounding oceans with a horizontal resolution of $0.1^{\circ}$ and a vertical resolution of $10 \mathrm{~m}$ in the upper $300 \mathrm{~m}$ [40]. Compared with existing observations (e.g., moorings, drifters and fields survey) which are not assimilated into the model, BRAN performs well in the Indonesian Seas and surrounding ocean and can especially capture the realistic details of seasonal circulation and its interactions with various topographic features [41-43]. The entire dataset covers the period from January 1994 to August 2016. The daily outputs of sea level, zonal velocity, meridional velocity, potential temperature and salinity in the upper $300 \mathrm{~m}$ from January 1994 to December 2015 are used for the instability analysis.

To compare the time-varying signals of SSH between BRAN and AVISO, an empirical orthogonal function (EOF) analysis is performed to both daily BRAN and AVISO SSH data with a daily resolution from 1994 to 2015. The first two modes of BRAN and AVISO reveal good resemblance in both spatial patterns and principal components (PC), and their cumulative explained variances are $64.42 \%$ and $63.89 \%$, respectively, which can describe the main characteristics of SSH variations in the Indonesian Seas and surrounding oceans. The spatial patterns and PCs of EOF mode 1 from BRAN and AVISO are displayed in Figure 2. Mode 1, respectively, explains $45.55 \%$ and $42.89 \%$ of the total variance in the BRAN and AVISO. BRAN and AVISO share a similar spatial pattern for EOF mode 1 (Figure $2 \mathrm{a}, \mathrm{b}$ ). The time series of two PCs also match favorably with a high correlation coefficient of 0.98 . The EOF mode 1 physically characterizes the large-scale variations of $\mathrm{SSH}$ in response to wind forcing dominantly modulated by the El Niño-Southern Oscillation (ENSO) [31].

The spatial patterns and PCs for EOF mode 2 of SSH from BRAN and AVISO are shown in Figure 3. BRAN captures the EOF mode 2 of observed SSH field faithfully, not only in spatial patterns (Figure 3a,b) but also in PCs (Figure 3c). The variances explained by the EOF mode 2 are $18.87 \%$ and $21 \%$ for BRAN and AVISO, respectively, and the correlation coefficient between two PCs is 0.98 . From the PCs (Figure 3c), it is clear that the EOF mode 2 represents the seasonal SSH variations in the Indonesian Seas and surrounding oceans. For example, Figure 3a,b indicate the surface circulations in the Sulu Sea and southern SCS exhibit a clear seasonal cycle, with an anticyclonic circulation during summer and a cyclonic circulation during winter, which has been proved based on both numerical models and observations $[44,45]$. The fact that BRAN simulates successfully the first two EOF modes of observed SSH signals is important since the large-scale circulation patterns tend to modulate mesoscale eddy activities.

\subsection{Eddy Detection and Tracking Algorithm}

Numerous automatic eddy detection algorithms have been developed based on the physical or geometric criteria, and they can be divided into three categories: (1) the physical parameter method, such as the Okubo-Weiss parameter method [46]; (2) the flow geometry method, including the winding-angle method [18,47] and the vector geometry method [48]; (3) the SSH-based method [2,17,35]. However, not all algorithms are suitable for identifying mesoscale eddies in the Indonesian Seas according to three reasons. Firstly, the SSH-based method performs better than the Okubo-Weiss parameter method because of its ability to avoid noise and excess eddy detections [2]. Secondly, the flow geometry algorithms require higher resolution data to get an accurate flow field to identify eddies, and the existing observational data in the Indonesian Seas cannot satisfy this demand [35]. Therefore, we adopted 
the SSH-based method developed by Faghmous et al. [17] (hereafter JHF15) which has been applied in the Kuroshio Extension Region [10], the Bay of Bengal [36] and the Southeastern Indian Ocean [12]. JHF15 identifies an eddy as a closed SLA contour with a single extreme. It is considered as a parameter-free method in which no empirical parameters are applied and the identified eddies' edges depend only on the single extreme approximation. In this study, both altimeter data and model outputs are used for eddy detection. For each dataset, all identified eddies larger than 9 corresponding grid cells are kept, to avoid some spurious features, and more details of JHF15 refer to Faghmous et al. [17]. The reader should note that the results in Section 3 are only from the altimeter data, while eddy detections from the model outputs are used to assess the capability of BRAN in terms of capturing mesoscale eddies.

(a)

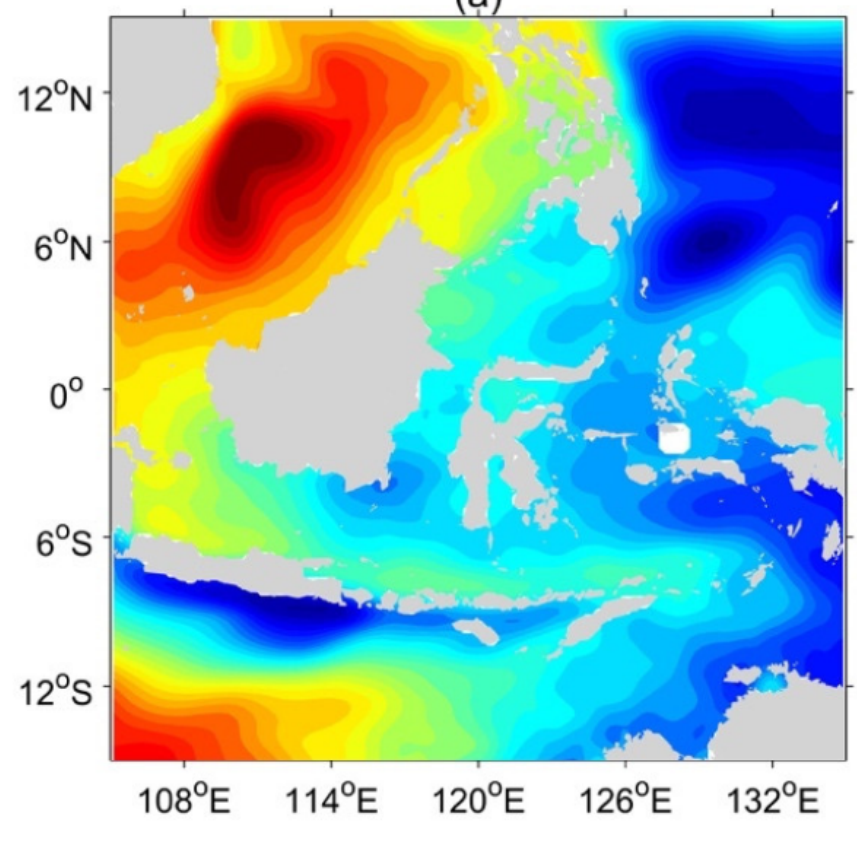

(b)

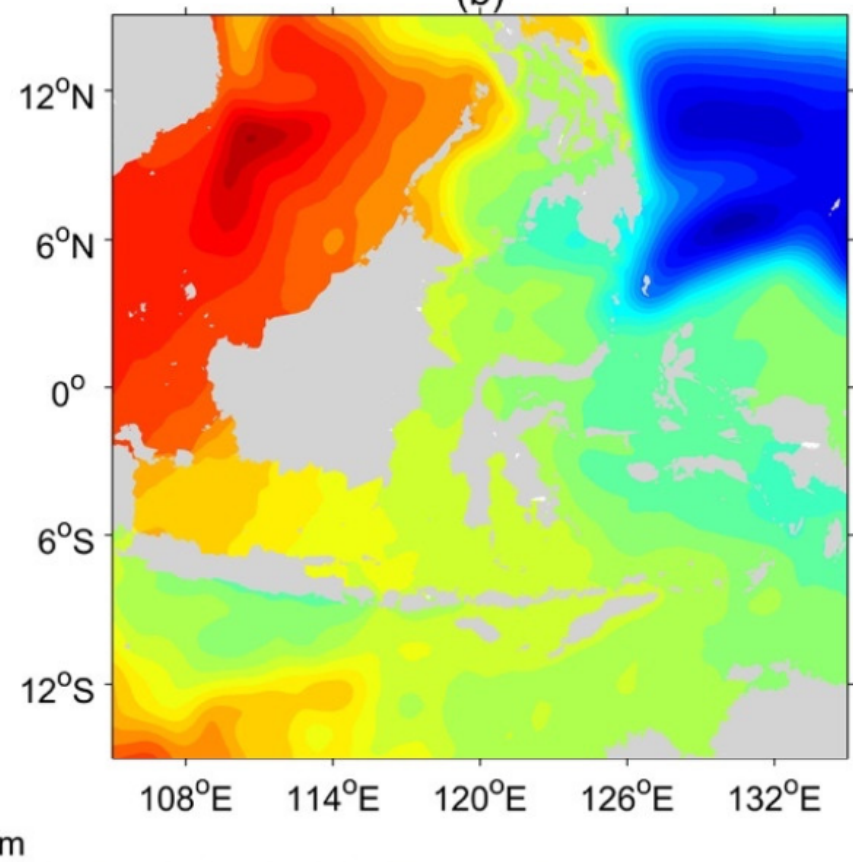

$\mathrm{cm}$

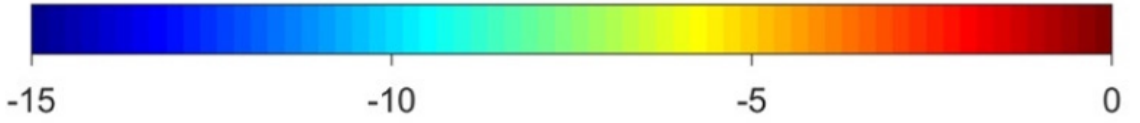

(c)

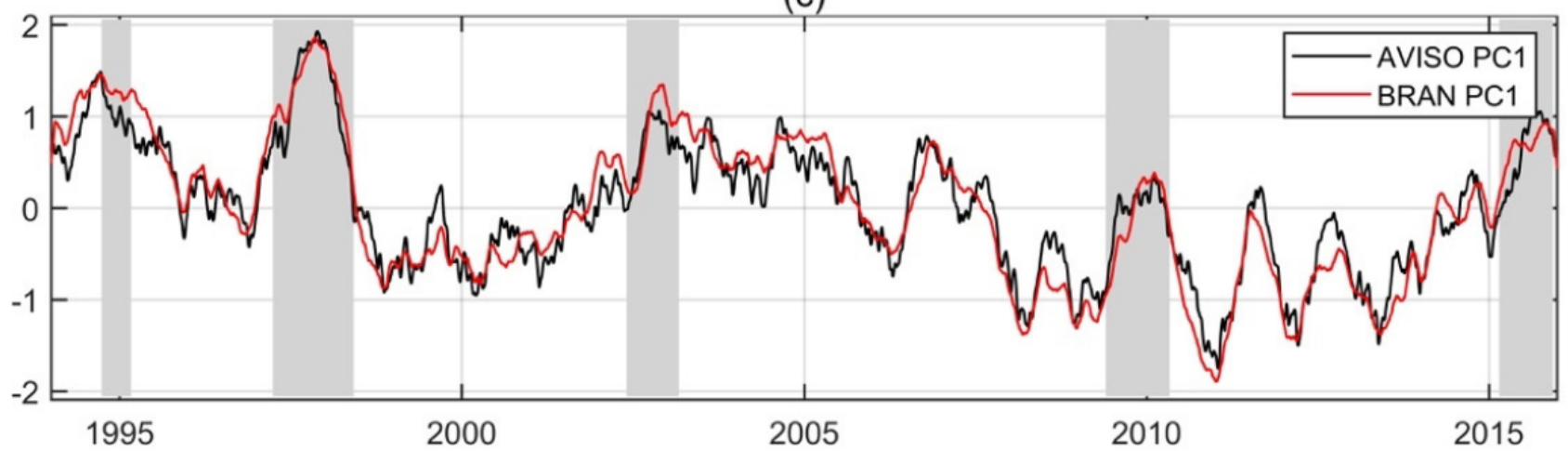

Figure 2. Spatial pattern of empirical orthogonal function mode 1 of sea surface height from (a) AVISO and (b) BRAN. (c) Principal component of empirical orthogonal function mode 1 from AVISO (black line) and BRAN (red line). The gray shadings in (c) represent El Niño events. 
(a)

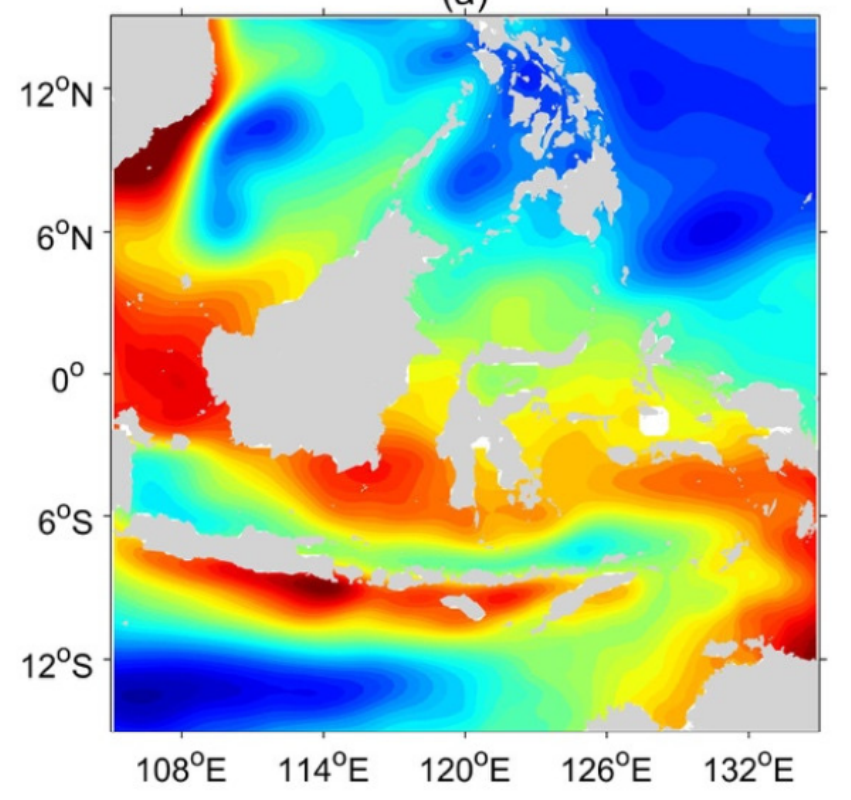

(b)

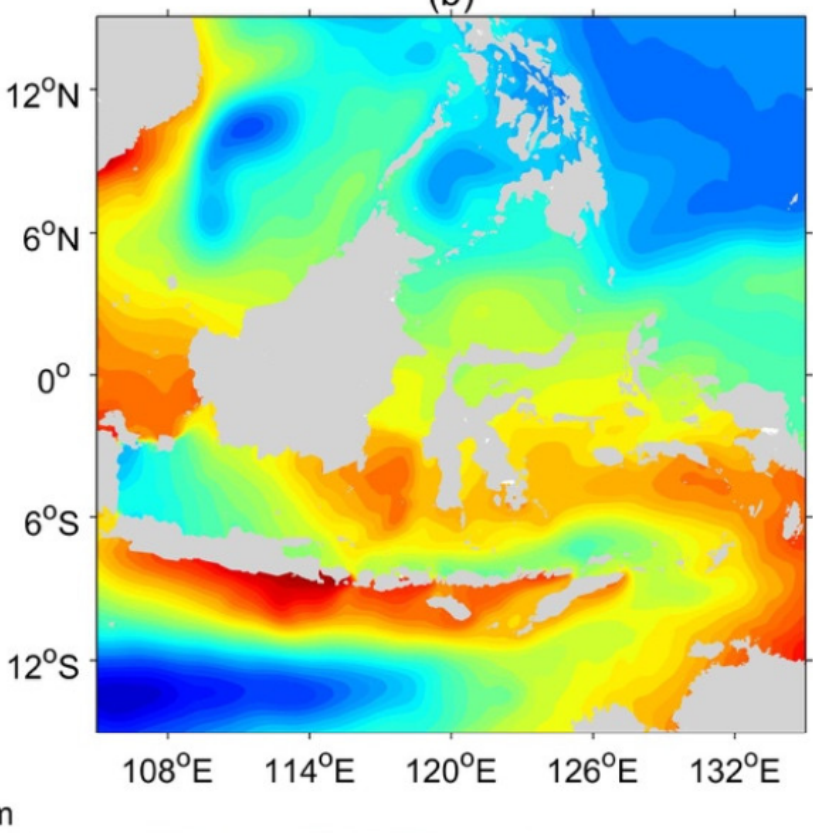

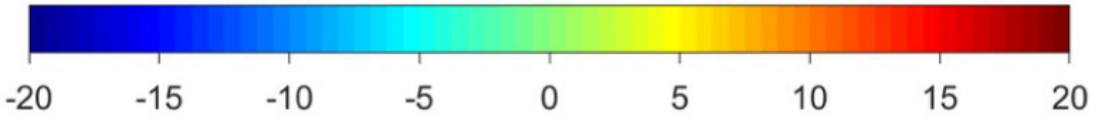

(c)

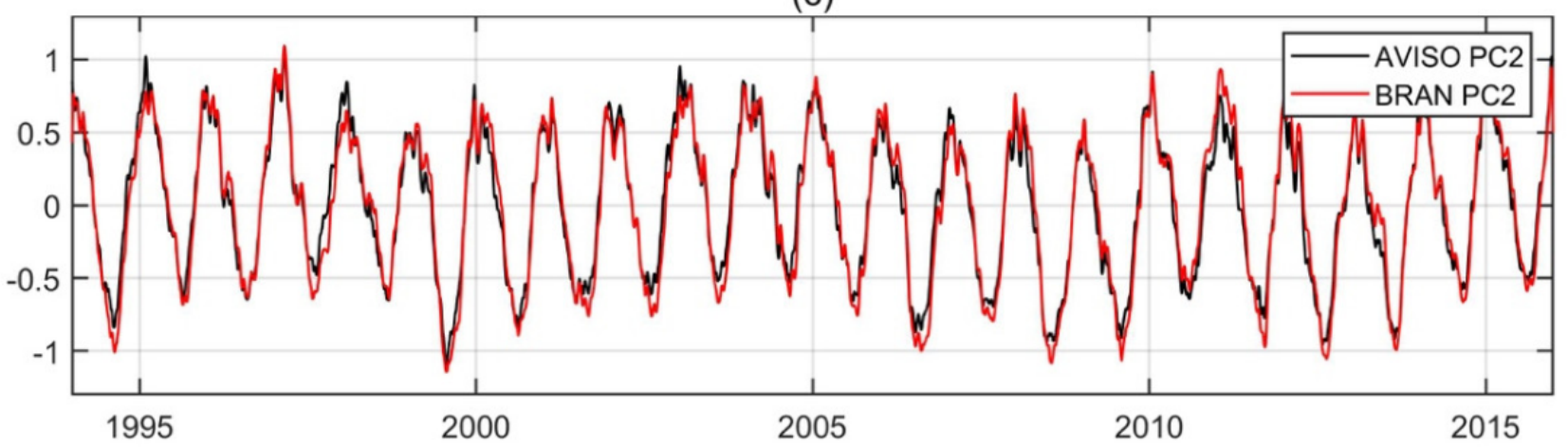

Figure 3. Spatial pattern of empirical orthogonal function mode 2 of sea surface height from (a) AVISO and (b) BRAN. (c) Principal component of empirical orthogonal function mode 2 from AVISO (black line) and BRAN (red line).

After eddies are detected in each daily SLA snapshot, they are tracked by an algorithm developed by Penven et al. [49]. The nondimensional distance of an eddy pair with the same polarity from two consecutive maps is defined as:

$$
D_{e_{1}, e_{2}}=\sqrt{\left(\frac{\Delta D}{D_{0}}\right)^{2}+\left(\frac{\Delta A}{A_{0}}\right)^{2}+\left(\frac{\Delta a}{a_{0}}\right)^{2}},
$$

where $\Delta D, \Delta A$ and $\Delta a$ are, respectively, the differences in eddy centroid location, surface area and amplitude between $e_{1}$ and $e_{2}$ in two consecutive maps; and the characteristic length scale $D_{0}$, the characteristic surface area $A_{0}$, and the characteristic amplitude $a_{0}$ are $25 \mathrm{~km}, \pi 60^{2} \mathrm{~km}^{2}$ and $2 \mathrm{~cm}$, respectively. The smaller $D_{e_{1}, e_{2}}$, the higher similarity of the eddy pair. Due to the sampling errors and measurement noise of satellite altimeter, some eddies may disappear at some time and reappear several time steps later. If an eddy moves into the gap among satellites' orbits, it will also vanish in the SLA map. To solve this problem, we repeat this tracking algorithm for a longer time step, from 2 to 7 days, for those unpaired eddies. We also set the maximum search distance $\Delta D$ to $150 \mathrm{~km}$ per week 
to avoid eddies jumping to another track. Following He et al. [34] and Zhang et al. [12], the number of eddy tracks and the number of eddies are different. The former is counted when an eddy track is once identified, while the latter is the total number of eddies along the eddy tracks.

\subsection{Definition of Eddy Properties}

The amplitude of eddy $a$ is defined as:

$$
a=\left|S L A_{\text {center }}-\left\langle S L A_{\text {edge }}\right\rangle\right|,
$$

where $\left\langle S L A_{\text {edge }}\right\rangle$ is the mean value of SLA at the eddy edge.

The surface area of eddy $A$ is the area delimited by the outermost contour of SLA, the eddy edge, whereas its apparent radius $R$ corresponds to the radius of an equivalent circular eddy with the same area. Thus, $R$ is calculated as:

$$
R=\sqrt{A / \pi} .
$$

The mean EKE of eddy is calculated as:

$$
\overline{E K E}=\frac{\iint_{s} \frac{1}{2}\left(u_{g}^{\prime 2}+v_{g}^{\prime 2}\right) d x d y}{A}
$$

where $u_{g}^{\prime}$ and $v_{g}^{\prime}$ are the zonal and meridional components of geostrophic velocity anomaly, respectively, calculated from SLA.

The mean vorticity of eddy is calculated as:

$$
\bar{\xi}=\frac{\iint_{\mathcal{S}} \frac{1}{2}\left(\frac{\partial v_{g}^{\prime}}{\partial x}-\frac{\partial u_{g}^{\prime}}{\partial y}\right) d x d y}{A} .
$$

\subsection{Instability Analysis}

The EKE is generally converted from mean-flow kinematic energy (MKE) through barotropic instability and Kelvin-Helmholtz instability or from eddy potential energy (EPE) via baroclinic instability [3-5,50]. Therefore, the energy conversion rates for the above three instabilities are calculated as follows [3,12,50]:

Barotropic conversion rate (BTR) from MKE to EKE via barotropic instability, depending on horizontal shears of mean flow, is defined as:

$$
B T R=-\left(\overline{u^{\prime} u^{\prime}} \frac{\partial \bar{u}}{\partial x}+\overline{u^{\prime} v^{\prime}} \frac{\partial \bar{v}}{\partial x}+\overline{u^{\prime} v^{\prime}} \frac{\partial \bar{u}}{\partial y}+\overline{v^{\prime} v^{\prime}} \frac{\partial \bar{v}}{\partial y}\right)
$$

Kelvin-Helmholtz conversion rate (KHR) from MKE to EKE via Kelvin-Helmholtz instability depending on vertical shears of mean flow and Reynolds stresses, is defined as:

$$
K H R=-\left(\overline{u^{\prime} w^{\prime}} \frac{\partial \bar{u}}{\partial z}+\overline{v^{\prime} w^{\prime}} \frac{\partial \bar{v}}{\partial z}\right)
$$

Baroclinic conversion rate $(B C R)$ from EPE to EKE via baroclinic instability is defined as:

$$
B C R=-\frac{g \overline{\rho^{\prime} w^{\prime}}}{\rho_{0}}
$$

where $\rho_{0}$ is the background density set to $1030 \mathrm{~kg} / \mathrm{m}^{3}$.

The overbars and primes represent time mean ( 1 month) and anomalies from time mean, respectively. 


\section{Results}

In the Indonesian Seas, a total of 46,676 AEs (Figure 4a) and 47,004 CEs (Figure 4b) are identified from January 1993 to December 2018. Most identified eddies are concentrated on four larger and deeper basins (i.e., the Sulu Sea, Sulawesi Sea, Maluku Sea and Banda Sea). Due to the shallower depth $(<200 \mathrm{~m})$ and smaller basin scale, fewer eddies are detected in the rest of the Indonesian Seas. To obtain robust statistical description for eddy properties, eddies with their amplitudes larger than $2 \mathrm{~cm}$ are analyzed in our study, with the consideration that the accuracy of SLA gridded data from AVISO is about $2 \mathrm{~cm}[15,51]$.
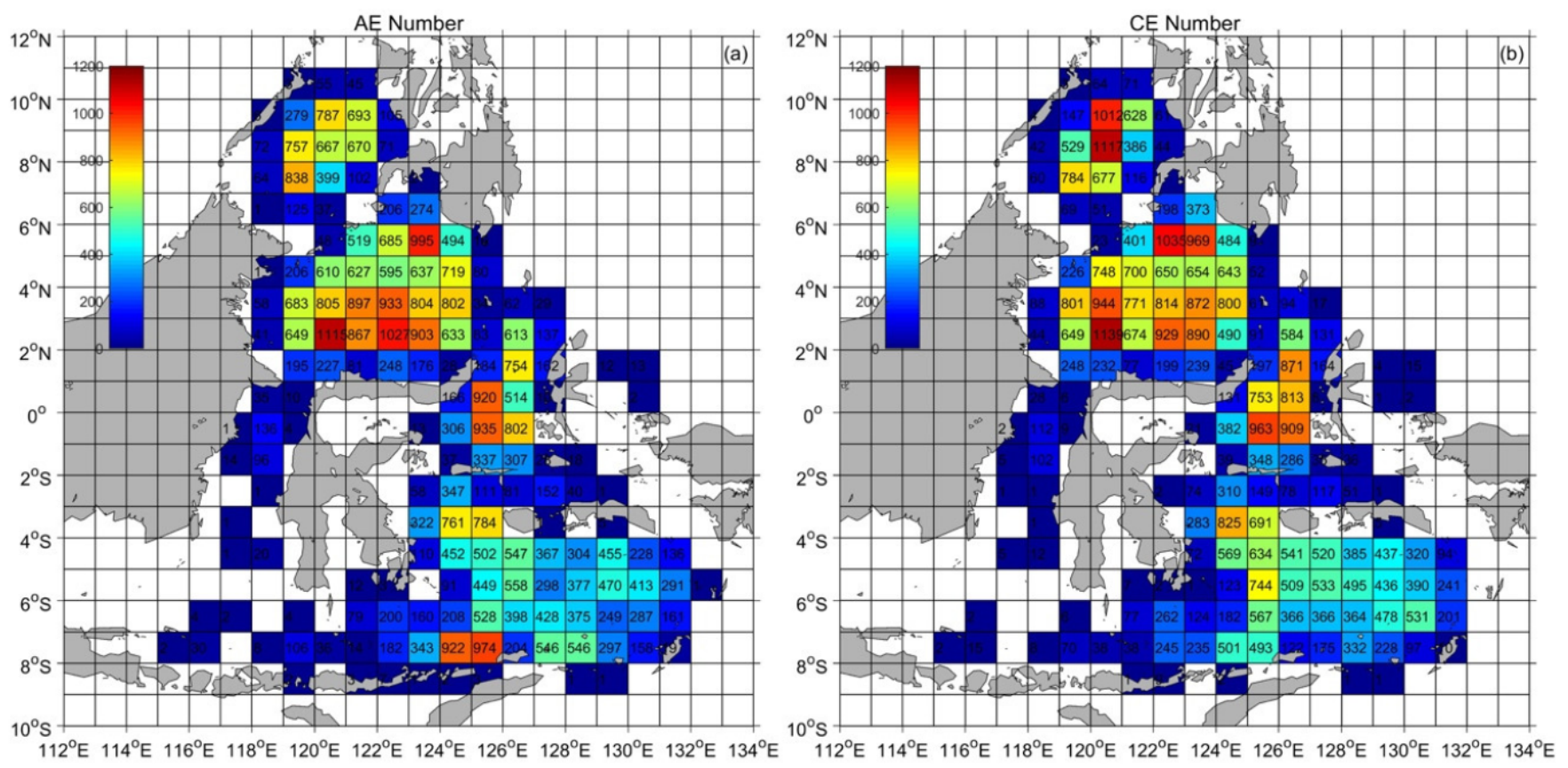

Figure 4. Spatial distribution of the numbers of identified (a) anticyclonic (AE) and (b) cyclonic (CE) eddies in the Indonesian Seas over the 1993-2018 period.

\subsection{Eddy Geneis and Decay}

The spatial distributions of the numbers of eddy genesis and decay events for $\mathrm{AE}$ and $C E$ are shown in Figure 5. The locations of eddy for generation and decay are the first and the last point in each eddy track, respectively. Because the minimum resolvable temporal scale of gridded SLA product from AVISO is about 10 days [52], we excluded those eddies with a lifespan shorter than 10 days. Consequently, a total of $469 \mathrm{AE}$ tracks and $500 \mathrm{CE}$ tracks are identified in the Indonesian Seas. AE tracks in the Sulu Sea, Sulawesi Sea, Maluku Sea and Banda Sea, respectively, account for $15 \%, 53 \%, 7 \%$ and $25 \%$ of the total AE tracks, while the proportion of $\mathrm{CE}$ tracks are $15 \%, 52 \%, 7 \%$ and $27 \%$, respectively. Hence, no apparent regional preference for $\mathrm{AE}$ and $\mathrm{CE}$ is found in the Indonesian Seas as is also observed in the Tropical Atlantic Ocean [19]. Due to the removal of SLA data in the area shallower than $200 \mathrm{~m}$, the eddy generation and decay are less frequent near the coast. It is interesting that both $\mathrm{AE}$ and $\mathrm{CE}$ preferentially generate in the areas north of Ombai Strait (Figure 5a,b), which may result from the interactions of intense mean flow with topographic features $[53,54]$. However, there are some differences of the geographical pattern for the formation and decay between $\mathrm{AE}$ and $\mathrm{CE}$. We find that the generation of $\mathrm{AE}$ is concentrated on the southeastern portion of the Sulu Sea (Figure 5a) while CE tend to form in northeastern portion of the Sulu Sea (Figure 5b). Additionally, the larger value of $\mathrm{CE}$ formation southwest of the Mindanao Island may partially result from the interaction between eastward currents and the coastline $[53,54]$. In the Sulawesi Sea, AE usually decays in the central and western part (Figure $5 \mathrm{c}$ ) while the death of $\mathrm{CE}$ concentrates on the western and northeastern part (Figure $5 \mathrm{~d}$ ). 

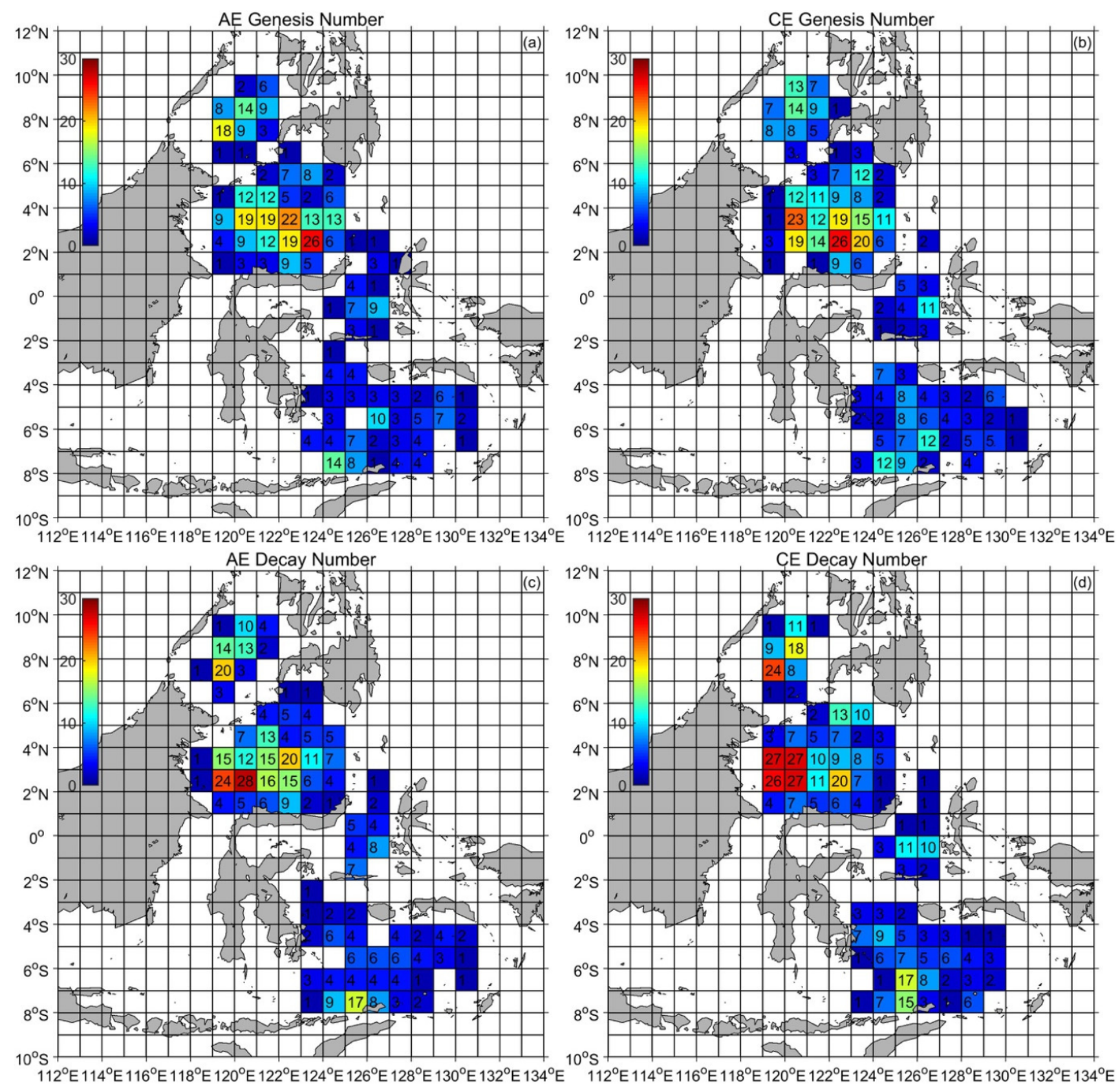

Figure 5. Spatial distribution of eddy genesis and decay events over the 1993-2018 period: (a) AE genesis events, (b) CE genesis events, (c) AE decay events and (d) CE decay events. The unit is the number of events.

\subsection{Eddy Propagation}

The propagation velocities are calculated by a forward difference scheme for eddy centroid displacement every day. The velocities of each eddy track were further filtered using a central moving average of 7 days to reduce the random noise and then averaged in each $0.25^{\circ} \times 0.25^{\circ}$ grid, following He et al. [34]. Figure 6 displays the mean propagation velocity fields and the standard deviation (STD) of azimuth of propagation direction relatively to the west for AE and CE. In the Sulu Sea, the AE (Figure 6a) and CE (Figure 6b) translation speed are approximately $2.3 \pm 1.0 \mathrm{~cm} / \mathrm{s}$ and $0.9 \pm 0.5 \mathrm{~cm} / \mathrm{s}$, respectively. AEs move southeastward at the northeastern half basin because of the advection of mean flow from the Mindoro Strait during boreal spring and summer when AEs are more frequent (Figure 6a). In the Sulawesi Sea, the AE translation speed is approximately $2.5 \pm 2.3 \mathrm{~cm} / \mathrm{s}$, with a westward propagation in the central basin (Figure 6a). The CE migrations across the entire basin are significantly affected by the intense intrusion of MC (Figure 6b), with a 
speed of $6.3 \pm 2.7 \mathrm{~cm} / \mathrm{s}$. In the Maluku Sea, all eddies propagate southwestward, which is parallel to the long axis of basin, at a velocity of $1.9 \pm 0.7 \mathrm{~cm} / \mathrm{s}$ for AE and $1.7 \pm 0.6 \mathrm{~cm} / \mathrm{s}$ for $\mathrm{CE}$ (Figure $6 \mathrm{a}, \mathrm{b}$ ). In the Banda Sea, the CEs are advected by the eastward mean flow during austral summer with more CEs (Figure 6b). More frequent AEs move southeastward with mean flow in the austral spring and autumn (Figure 6a). The corresponding propagation speeds of AE and CE in the Banda Sea are $5.7 \pm 2.5 \mathrm{~cm} / \mathrm{s}$ and $3.9 \pm 2.5 \mathrm{~cm} / \mathrm{s}$ (More details refer to Section 3.5 and Appendix A).
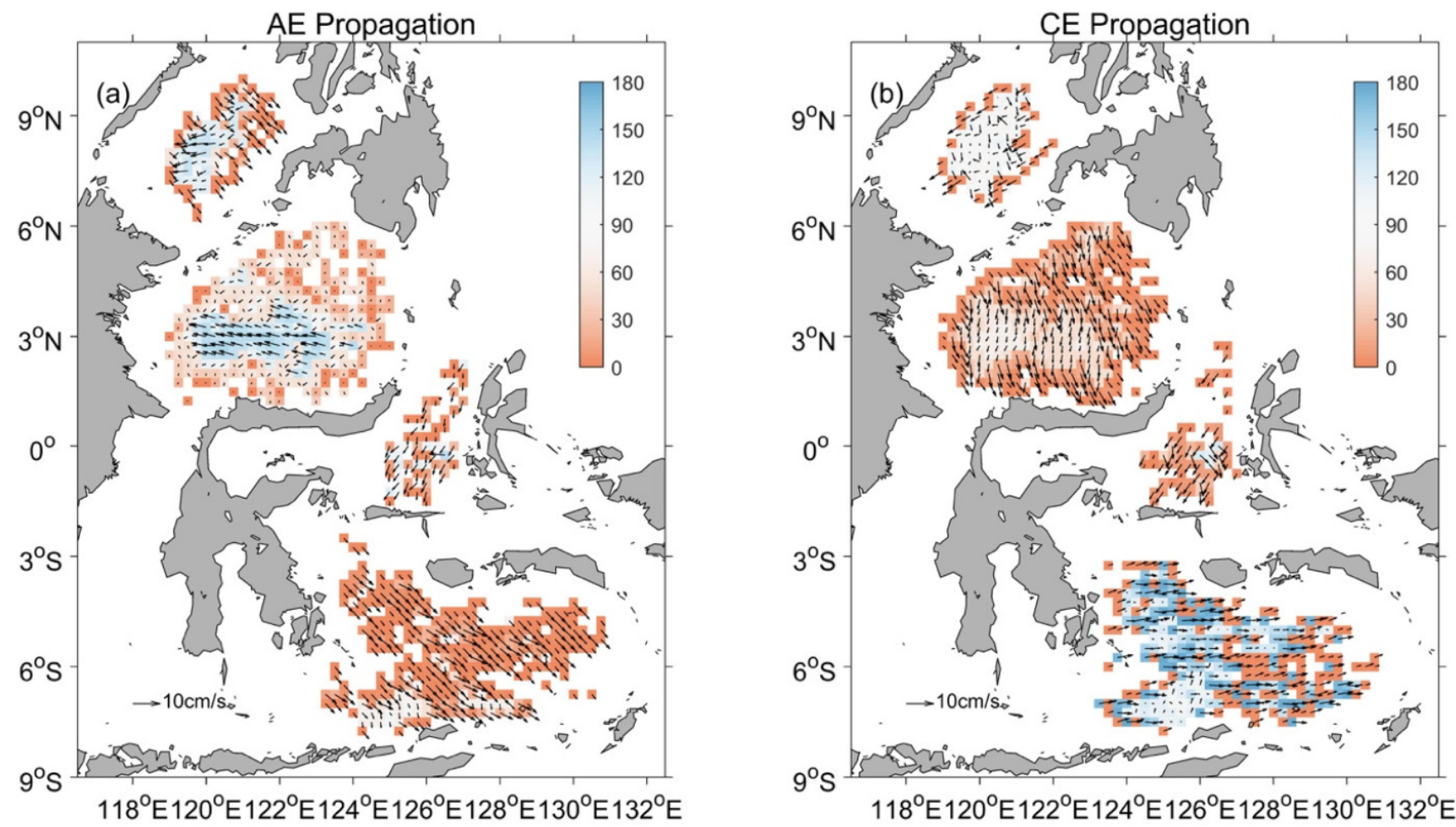

Figure 6. Spatial distribution of propagation velocity vectors (black arrows, unit: $\mathrm{cm} / \mathrm{s}$ ) for (a) AE and (b) CE over the 1993-2018 period. The color shading represents the standard deviation (STD) of propagation azimuths relative to west at each $0.25^{\circ} \times 0.25^{\circ}$ grid (units: degree).

\subsection{Eddy Lifespan}

In this study, the lifespan of an eddy is defined as the number of days between the genesis and decay of the eddy. The upper-tail cumulative histograms of the eddy lifespan for the Sulu Sea, Sulawesi Sea, Maluku Sea and Banda Sea are presented in Figure 7. The short-lived (10 30 days, referenced in [15]) AEs (CEs) account for 73\% (84\%), 85\% (86\%), $100 \%(94 \%)$ and $86 \%(80 \%)$ in the Sulu Sea, Sulawesi Sea, Maluku Sea and Banda Sea, respectively. This suggests that most mesoscale eddies in the Indonesian Seas are shortlived, as also observed in the tropical oceans including the equatorial current systems and tropical oceanic warm pools [15]. The lifespans of AE and CE have a generally similar distribution in all these seas with a rapid decrease within 40 days and a slow decrease beyond 40 days except for the Maluku Sea where the eddy lifespan is mostly shorter than 30 days. However, there are some differences between AE and CE in each sea. In the Sulu Sea (Figure 7a), the portion of $\mathrm{AE}$ with lifespan larger than 30 days, $27 \%$, is higher than $\mathrm{CE}$ with a percentage of $16 \%$. The distributions of lifespan for eddies are more skewed to high values for $\mathrm{AE}$ than $\mathrm{CE}$ in the Sulawesi Sea (Figure $7 \mathrm{~b}$ ). For the relatively longevous eddies, CEs are more abundant than AEs in the Banda Sea, with a percentage of $20 \%$ (Figure 7d). 
(a) Sulu Sea

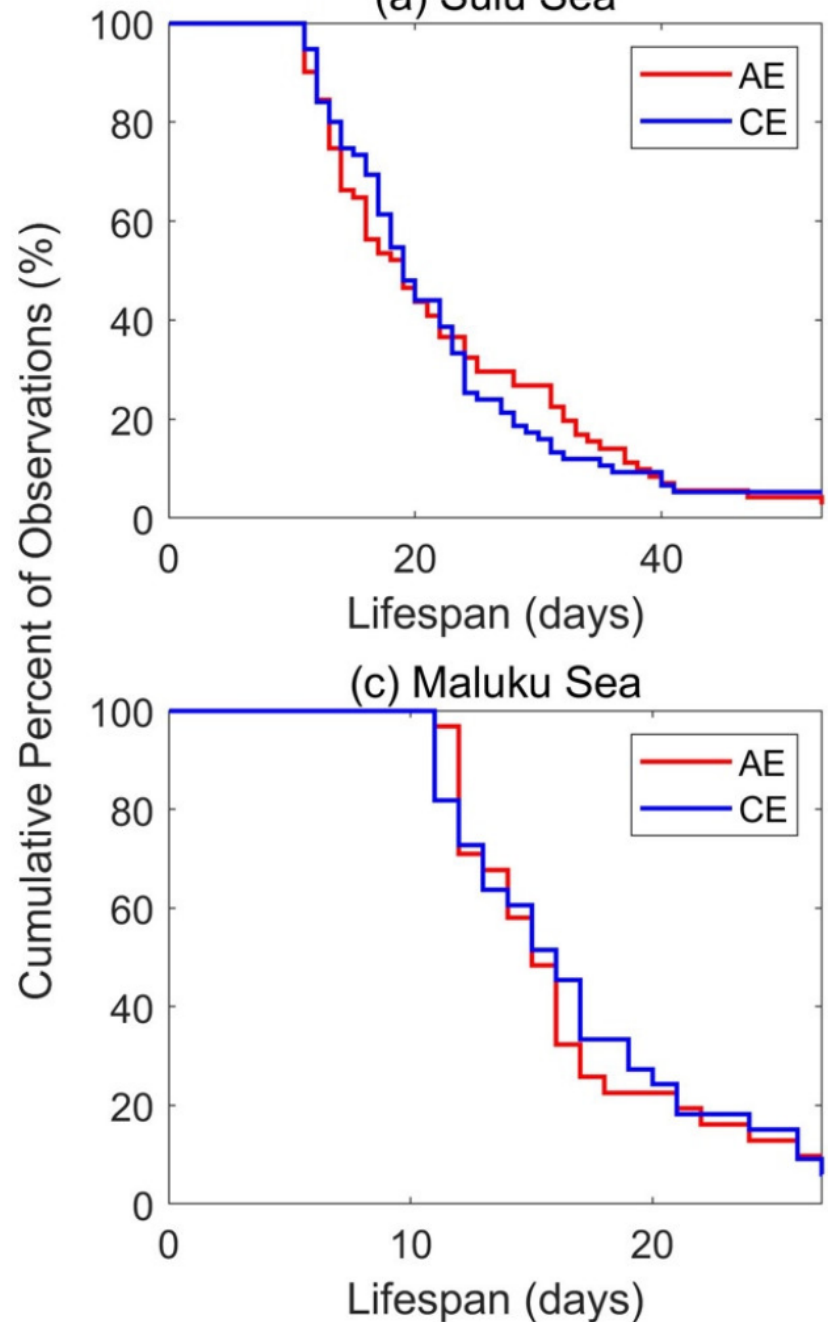

(b) Sulawesi Sea

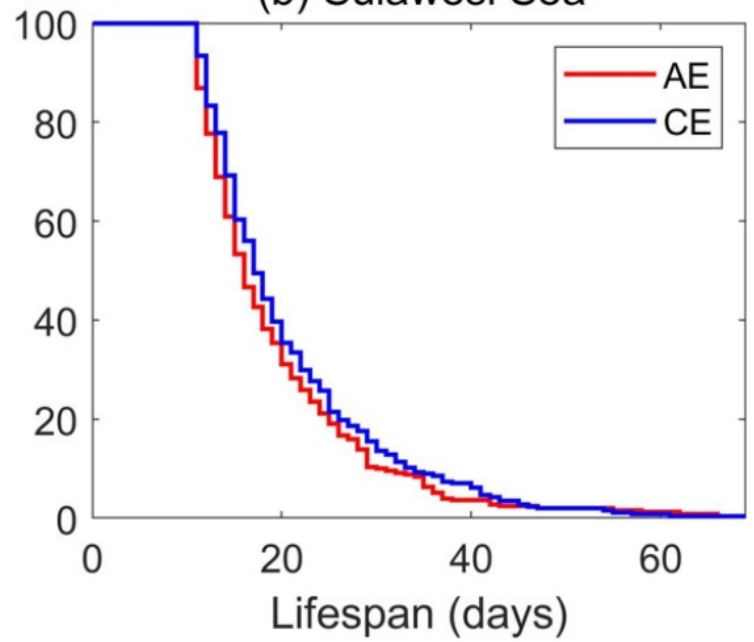

(d) Banda Sea

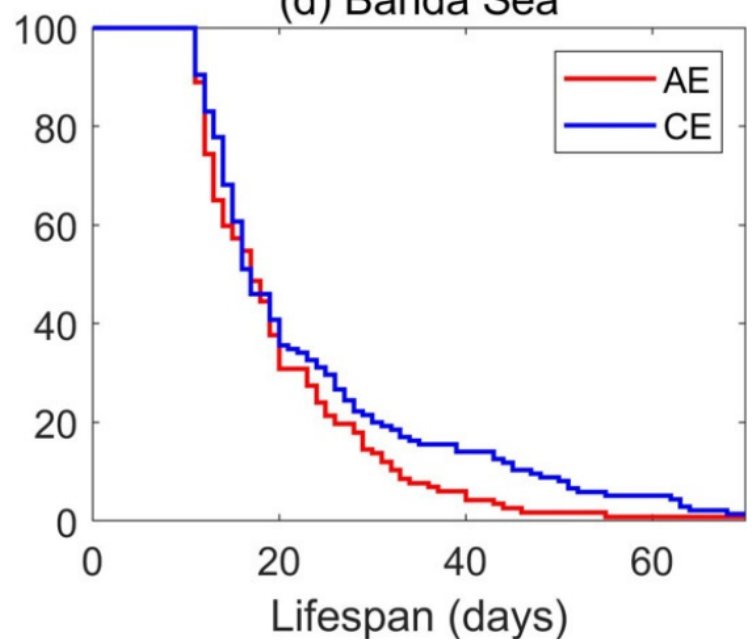

Figure 7. Upper-tail cumulative histograms of the eddy lifespan in the (a) Sulu Sea, (b) Sulawesi Sea, (c) Maluku Sea and (d) Banda Sea. The red and blue lines in each panel correspond to AE and CE, respectively.

\subsection{Distribution of Eddy Properties}

The spatial distributions of amplitude and radius for AEs and CEs averaged in $1^{\circ} \times 1^{\circ}$ grid are shown in Figure 8. Eddies have typical amplitudes of 2-6 cm and radiuses of $50-160 \mathrm{~km}$ in the Indonesian Seas. The patterns of amplitude (Figure $8 \mathrm{a}, \mathrm{b}$ ) are generally similar to those of radius (Figure $8 \mathrm{c}, \mathrm{d}$ ), indicating that the amplitude is positively correlated with the radius. Both amplitude (Figure $8 \mathrm{a}, \mathrm{b}$ ) and radius (Figure $8 \mathrm{c}, \mathrm{d}$ ) are larger in the interior basin and smaller near the coast for the Sulu Sea, Sulawesi Sea and Banda Sea. This may be due to the strong energy dissipation near the coast [34], and eddy growth in the central basin resulted from the eddy interactions [55]. Meanwhile the amplitude and radius for $\mathrm{AE}$ and $\mathrm{CE}$ in the Maluku Sea and Seram Sea are smaller due to small basin scale, as also observed in the Red Sea by Zhan et al. [47]. The large values of eddy radius are observed in the Banda Sea, where the maximum value of $157 \mathrm{~km}$ is observed in the central basin and the majority is more than $100 \mathrm{~km}$. Additionally, the amplitude and radius of CE (Figure 8b,d) are stronger than those of AE (Figure 8a,c) in the Sulawesi Sea, where $\mathrm{MC}$ intrudes into Sulawesi Sea as a cyclonic loop structure [22]. 

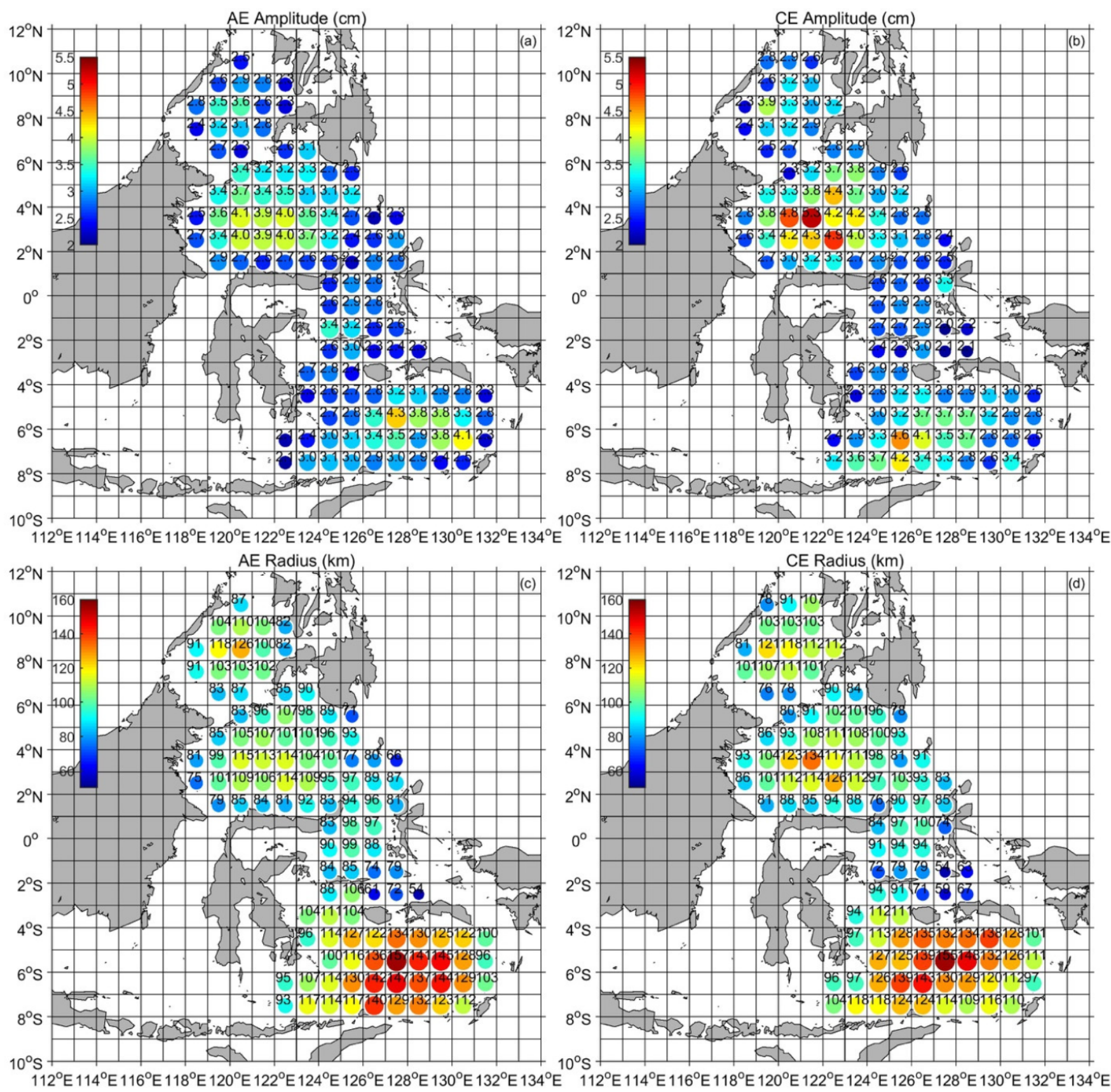

Figure 8. Spatial distribution (color spotted) of mean eddy properties over the 1993-2018 period: (a) AE amplitude, (b) CE amplitude, (c) AE radius and (d) CE radius. A value in each grid is averaged from eddies centered within this grid. The units of amplitude and radius are $\mathrm{cm}$ and $\mathrm{km}$, respectively.

Figure 9 displays the spatial distributions of mean EKE and mean relative vorticity for $\mathrm{AE}$ and $\mathrm{CE}$ averaged in $1^{\circ} \times 1^{\circ}$ grid. There is no significant difference between $\mathrm{AE}$ and CE in the spatial pattern of mean EKE in the Indonesian Seas. The spatial pattern of mean EKE is similar to that of amplitude, which indicates that the tangential speed of eddy is largely determined by amplitude [12,34]. Both the magnitude and variation of mean EKE in the Sulu Sea agree well with the estimate of He et al. [34]. The most energetic eddies are observed in the Sulawesi Sea and Seram Sea with high MKE [42,56]. MKE is converted to EKE through the barotropic pathway [3-5], which will be discussed in Section 4. Although high eddy amplitude is also observed in the central Banda Sea (Figure 8a,b), the value of mean EKE (Figure 9a,b) is smaller than those in the Sulawesi Sea due to larger eddy area (Figure $8 \mathrm{c}, \mathrm{d}$ ). The spatial distribution of mean relative vorticity for $\mathrm{AE}$ and $\mathrm{CE}$ are generally 
similar (Figure 9c,d). Eddies with high mean relative vorticity were found in the Sulawesi Sea and Seram Sea, which is similar to the distribution of mean EKE. However, compared with other eddy properties, high value of mean vorticity is located near the coast instead of in the interior basin. On the one hand, the sampling number of eddies is very small in the coastal area. On the other hand, strong lateral friction leads to strong horizontal shear of velocities in the coastal region [55].
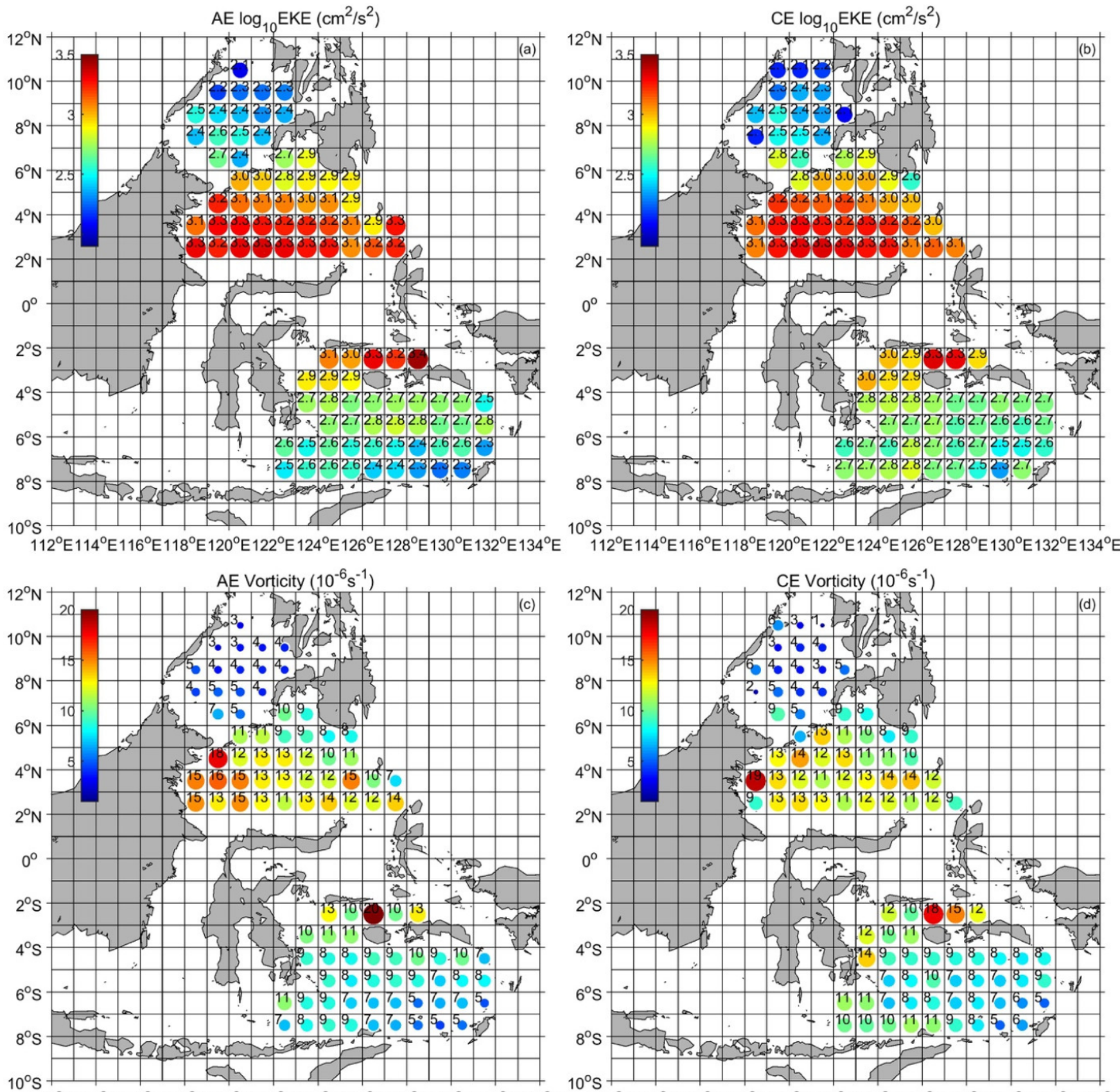

$112^{\circ} \mathrm{E} 114^{\circ} \mathrm{E} 116^{\circ} \mathrm{E} 118^{\circ} \mathrm{E} 120^{\circ} \mathrm{E} 122^{\circ} \mathrm{E} 124^{\circ} \mathrm{E} 126^{\circ} \mathrm{E} 128^{\circ} \mathrm{E} 130^{\circ} \mathrm{E} 132^{\circ} \mathrm{E} 134^{\circ} \mathrm{E}$

$112^{\circ} \mathrm{E} 114^{\circ} \mathrm{E} 116^{\circ} \mathrm{E} 118^{\circ} \mathrm{E} 120^{\circ} \mathrm{E} 122^{\circ} \mathrm{E} 124^{\circ} \mathrm{E} 126^{\circ} \mathrm{E} 128^{\circ} \mathrm{E} 130^{\circ} \mathrm{E} 132^{\circ} \mathrm{E} 134^{\circ} \mathrm{E}$

Figure 9. Spatial distribution (color spotted) of mean eddy properties over the 1993-2018 period: (a) the common logarithm of mean AE EKE, (b) the common logarithm of mean CE EKE, (c) mean AE vorticity and (d) mean CE vorticity. A value in each grid is averaged from eddies centered within this grid. The units of EKE and vorticity are $\mathrm{cm}^{2} / \mathrm{s}^{2}$ and $10^{-6} \mathrm{~s}^{-1}$, respectively. 


\subsection{Seasonal Variability}

The mean seasonal cycle of eddy properties in the Sulu Sea is shown in Figure 10. For $\mathrm{AE}$, the mean number (Figure 10a), amplitude (Figure 10b) and radius (Figure 10c) display similar patterns, which are large in boreal summer and small in boreal winter, with peak values of $0.4,3.7 \mathrm{~cm}$ and $123.5 \mathrm{~km}$ in August, respectively. The mean number, amplitude and radius of $\mathrm{CE}$ display similar patterns but in an opposite phase with $\mathrm{AE}$, with large values in boreal winter and small values in boreal summer (Figure 10a-c). The latitude of eddy centroid presents opposite seasonal variability between AE and CE (Figure 10d). This indicates more AEs than CEs in the northern Sulu Sea from November to February, while more CEs populate in the southern Sulu Sea from August to October. The mean EKE of CE have a seasonal cycle with a bimodal structure (Figure 10e), which reaches the annual maximum of $352.5 \mathrm{~cm}^{2} / \mathrm{s}^{2}$ in June, and then drops rapidly to the annual minimum of $239.6 \mathrm{~cm}^{2} / \mathrm{s}^{2}$ in October. From then it increases dramatically to the local maximum of $317.4 \mathrm{~cm}^{2} / \mathrm{s}^{2}$ in December and decreases to the local minimum of $248.6 \mathrm{~cm}^{2} / \mathrm{s}^{2}$ in January. While the mean EKE of AE shows a single peak in May with a value of $334.5 \mathrm{~cm}^{2} / \mathrm{s}^{2}$, and a single trough with a value of $204.2 \mathrm{~cm}^{2} / \mathrm{s}^{2}$ in March. The mean relative vorticity of CE (Figure 10f) also has a bimodal structure, in which two peaks exist in September and December, with corresponding values of $5.1 \times 10^{-6} \mathrm{~s}^{-1}$ and $4.4 \times 10^{-6} \mathrm{~s}^{-1}$, and two troughs appear in February and October with corresponding values of $3.5 \times 10^{-6} \mathrm{~s}^{-1}$ and $3.8 \times 10^{-6} \mathrm{~s}^{-1}$. No significant seasonal variation is observed for the mean relative vorticity of AE (Figure 10f). Although the magnitudes of monthly average eddy properties are different from He et al. [34] due to different limitations of amplitude in eddy identification algorithms, the seasonal cycle of eddy characteristics displays almost identical tendency not only for AE but also for CE.

Figure 11 displays the mean seasonal cycle of eddy properties in the Sulawesi Sea. The seasonal variations of mean number (Figure 11a), amplitude (Figure 11b) and radius (Figure 11c) of $\mathrm{AE}$ and $\mathrm{CE}$ follow the bimodal curves. For AE, the mean number, amplitude and radius reach annual minimum in September, with corresponding values of $0.6,3.2 \mathrm{~cm}$ and $97.6 \mathrm{~km}$, and then achieve annual maximum in boreal winter, with values of 1.0, $4.1 \mathrm{~cm}$ and $111.8 \mathrm{~km}$, respectively. From then they attain local minimum in May with corresponding values of $0.7,3.5 \mathrm{~cm}$ and $99.9 \mathrm{~km}$, and reach local maximum in July, with values of $0.8,3.6 \mathrm{~cm}$ and $105.2 \mathrm{~km}$, respectively. While the mean number, amplitude and radius of $\mathrm{CE}$ vary in an opposite phase compared with those of $\mathrm{AE}$ (Figure 11a-c). It is noted that CEs have larger amplitude than AEs through the whole year in the Sulawesi Sea. This further confirms the fact found above from the spatial perspective, the CE amplitude is larger than AE amplitude. The latitude of eddy centroid between $\mathrm{AE}$ and $\mathrm{CE}$ presents the opposite tendency in the Sulawesi Sea, with more AEs in the southern Sulawesi Sea from March to September while more CEs in the northern Sulawesi Sea from October to February (Figure 11d). Both the seasonal cycle of mean EKE and mean relative vorticity have bimodal structure for CE (Figure 11e,f). Two peaks appear in January with values of $1816 \mathrm{~cm}^{2} / \mathrm{s}^{2}$ and $12.9 \times 10^{-6} \mathrm{~s}^{-1}$ and May with values of $1688 \mathrm{~cm}^{2} / \mathrm{s}^{2}$ and $12.3 \times 10^{-6} \mathrm{~s}^{-1}$, respectively, while two troughs exist in April with values of $1480 \mathrm{~cm}^{2} / \mathrm{s}^{2}$ and $11.3 \times 10^{-6} \mathrm{~s}^{-1}$ and September with values of $1493 \mathrm{~cm}^{2} / \mathrm{s}^{2}$ and $11.2 \times 10^{-6} \mathrm{~s}^{-1}$, respectively. The mean EKE of AE have a similar pattern to that of CE, with two peaks in December and May and two troughs in April and September (Figure 11e). No apparent seasonal variations are observed for the mean relative vorticity of $\mathrm{AE}$ in the Sulawesi Sea, with a maximum value of $13.2 \times 10^{-6} \mathrm{~s}^{-1}$ and a minimum value of $11.5 \times 10^{-6} \mathrm{~s}^{-1}$ (Figure 11f). 
(a)

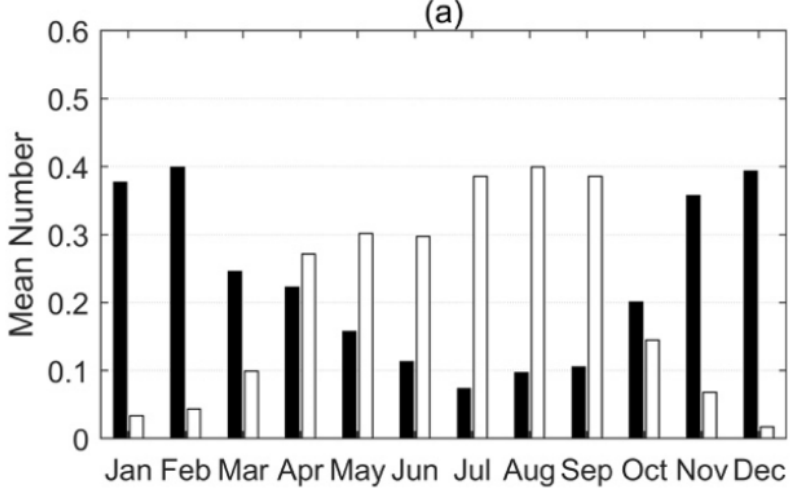

(c)

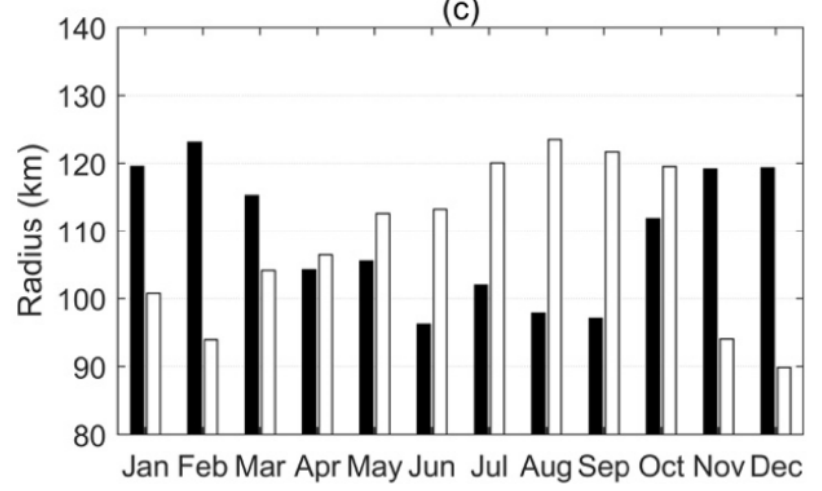

(e)

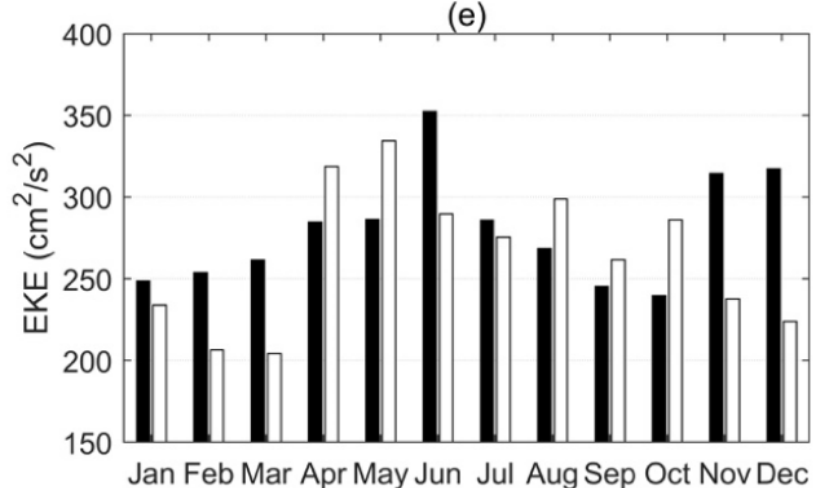

(b)

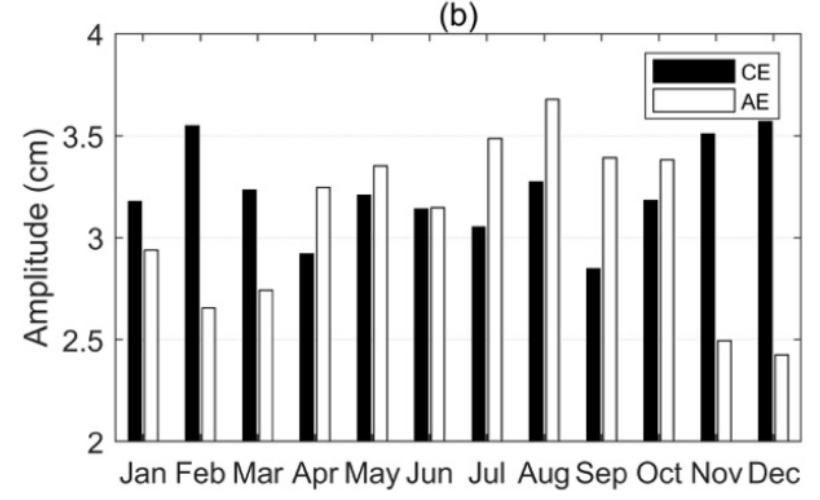

(d)

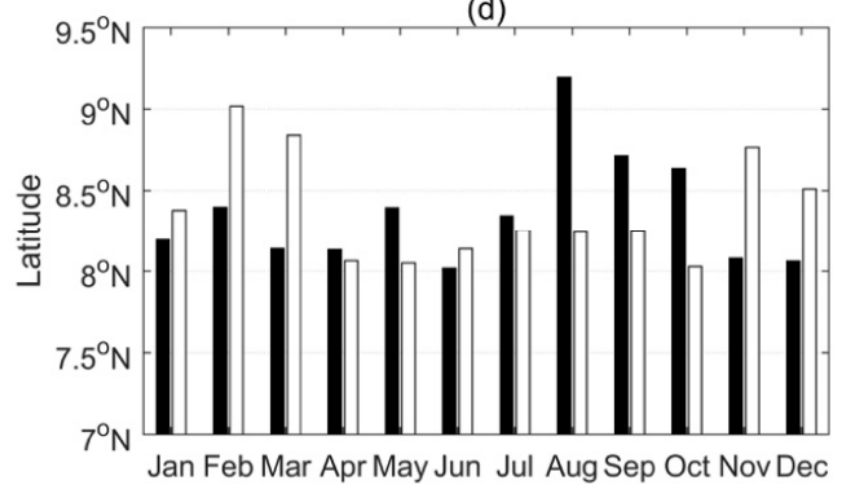

(f)

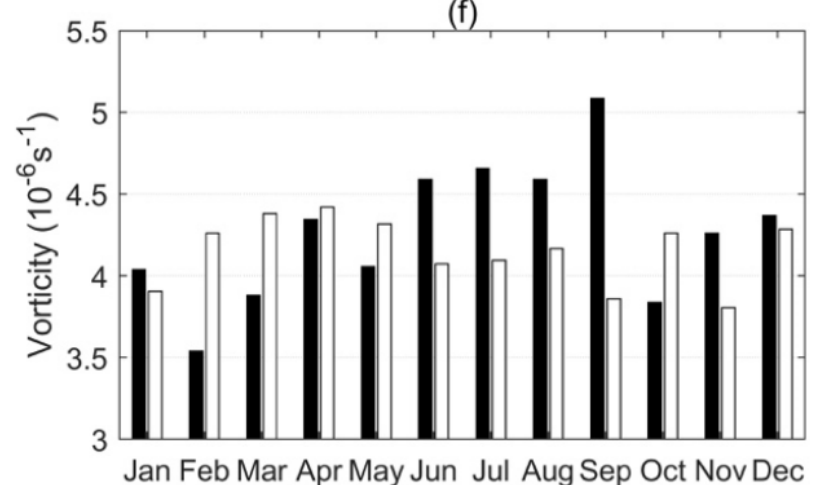

Figure 10. Seasonal cycles of eddy properties (black bars are for CE and white bars are for AE) in the Sulu Sea: (a) number of eddies, (b) amplitude, (c) radius, (d) central latitude, (e) mean EKE and (f) mean vorticity. The units of amplitude, radius, mean EKE and mean vorticity correspond to $\mathrm{cm}, \mathrm{km}, \mathrm{cm}^{2} / \mathrm{s}^{2}$ and $10^{-6} \mathrm{~s}^{-1}$.

The mean seasonal cycle of eddy properties in the Maluku Sea is shown in Figure 12. The monthly mean number of AE and CE are less than 0.2 in the Maluku Sea (Figure 12a). The amplitude of CE has a bimodal curve with annual maximum of $3.1 \mathrm{~cm}$ in February, annual minimum of $2.6 \mathrm{~cm}$ in July, local maximum of $2.8 \mathrm{~cm}$ in October and local minimum of $2.7 \mathrm{~cm}$ in December (Figure 12b). While there is no clear seasonal cycle of AE amplitude with the maximum of $3 \mathrm{~cm}$ in November and the minimum of $2.7 \mathrm{~cm}$ in July (Figure 12b). The seasonal variation of $C E$ radius is similar to that of $C E$ amplitude. Two peaks appear in March and October, with corresponding values of $98.7 \mathrm{~km}$ and $103.7 \mathrm{~km}$, and two troughs are in February and May, with corresponding values of $88.51 \mathrm{~km}$ and $91.4 \mathrm{~km}$ (Figure 12c). Like AE amplitude, the $\mathrm{AE}$ radius has no apparent seasonal cycle, with the maximum of $99.8 \mathrm{~km}$ in October and the minimum of $87.9 \mathrm{~km}$ in January (Figure 12c). AEs in the Maluku Sea prefer to locate south of the equator from July to November and appear north of equator from December to June (Figure 12d). On the contrary, CEs in the Maluku Sea tend to populate south of the equator in the first half of the year and north of the equator in the second half of the year (Figure 12d). 


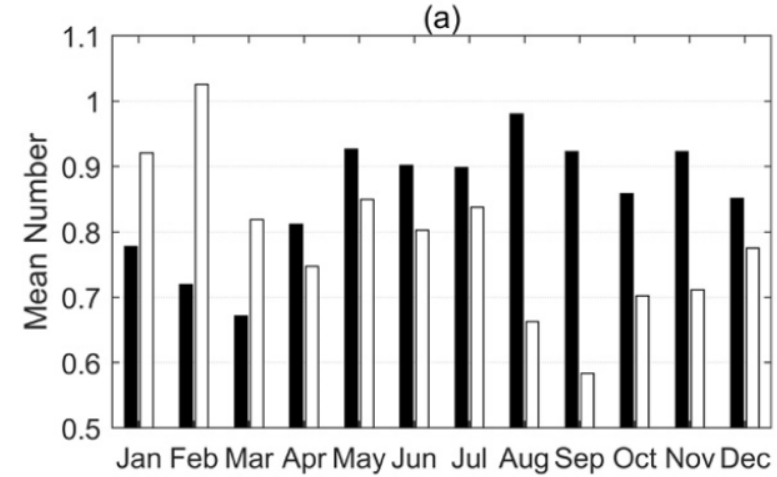

(c)

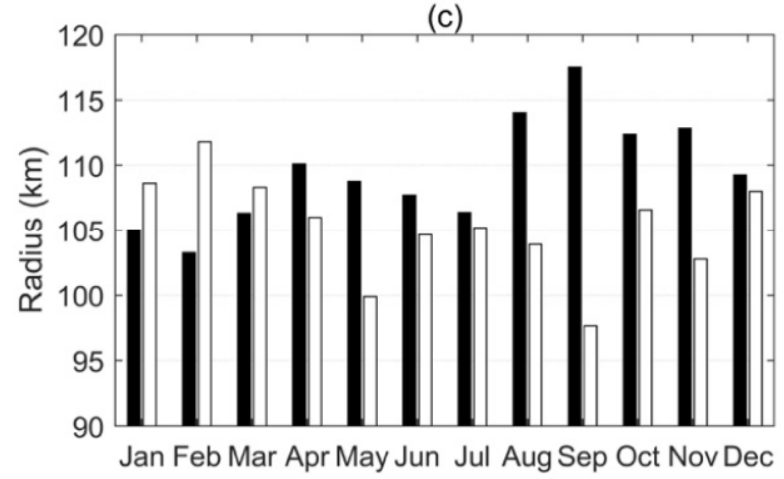

(e)

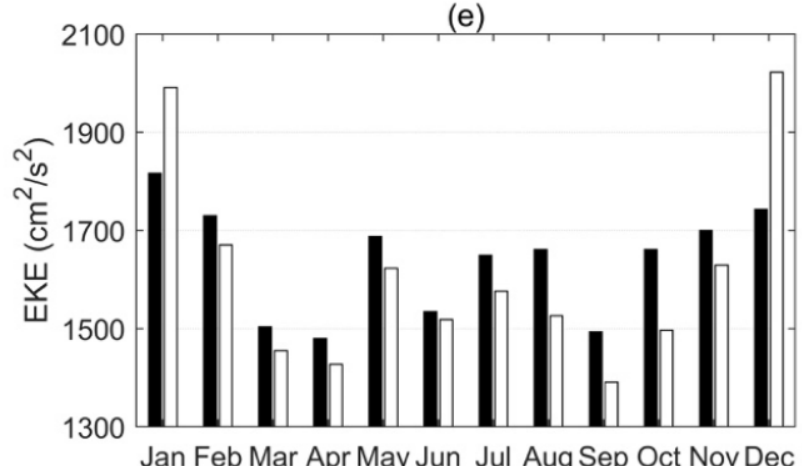

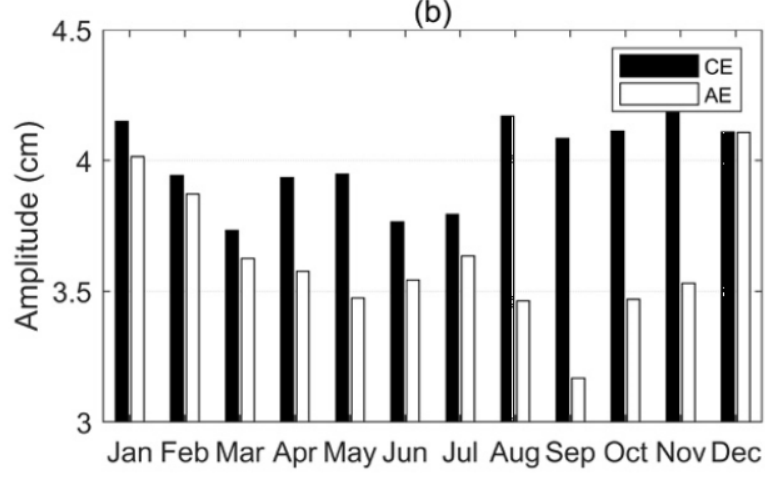

(d)

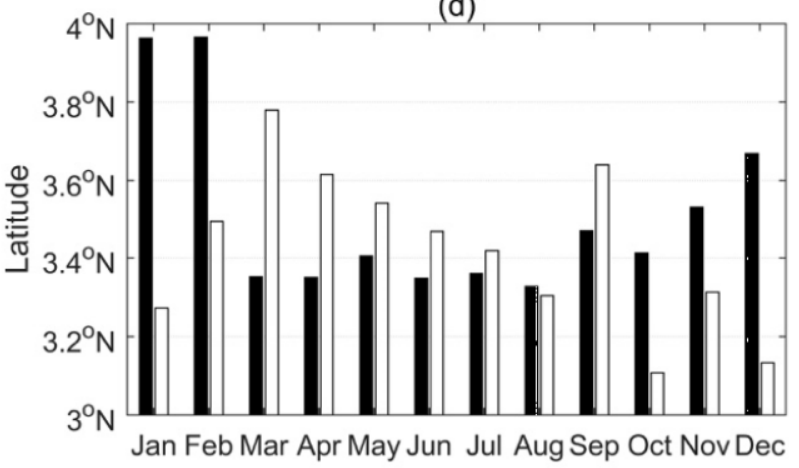

(f)

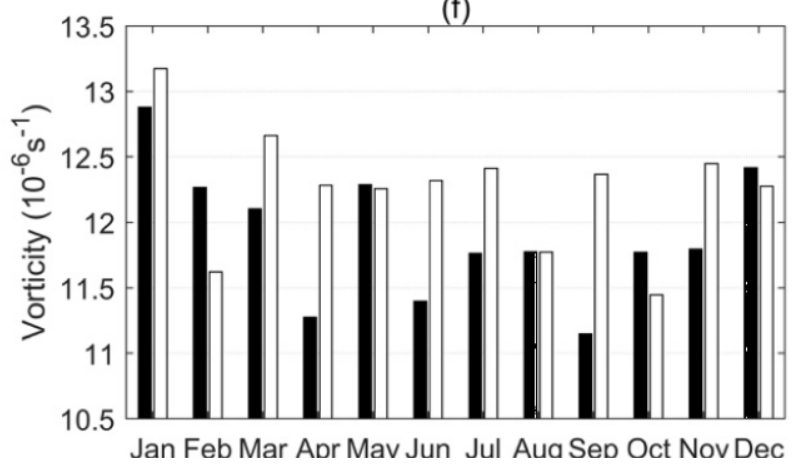

Figure 11. Seasonal cycles of eddy properties (black bars are for $\mathrm{CE}$ and white bars are for AE) in the Sulawesi Sea: (a) number of eddies, (b) amplitude, (c) radius, (d) central latitude, (e) mean EKE and (f) mean vorticity. The units of amplitude, radius, mean EKE and mean vorticity correspond to $\mathrm{cm}, \mathrm{km}, \mathrm{cm}^{2} / \mathrm{s}^{2}$ and $10^{-6} \mathrm{~s}^{-1}$.

Figure 13 shows the mean seasonal cycle of eddy properties in the Banda Sea. The mean number (Figure 13a), amplitude (Figure 13b) and radius (Figure 13c) of AE in the Banda Sea exhibit bimodal structure in seasonal variability. They reach the annual maximum in austral autumn with corresponding values of $0.6,3.6 \mathrm{~cm}$ and $139.9 \mathrm{~km}$, then drop to annual minimum in austral winter with the values of $0.3,3.0 \mathrm{~cm}$ and $124.6 \mathrm{~km}$, respectively. After achieving the minima, they increase to a local maximum with corresponding values of $0.4,3.2 \mathrm{~cm}$ and $137.2 \mathrm{~km}$ in austral spring and then decrease to a local minimum with the values of $0.2,3.1 \mathrm{~cm}$ and $122.1 \mathrm{~km}$ in austral summer, respectively. As shown in Figure 13a,b, the mean number and amplitude of CE hit peak in austral summer with corresponding values of 0.7 and $4.8 \mathrm{~cm}$. From then, they decrease gradually to the trough in austral winter with values of 0.3 and $2.9 \mathrm{~cm}$, respectively. Meanwhile, the $\mathrm{CE}$ radius reaches the maximum of $143.1 \mathrm{~km}$ in January and the minimum of $124.0 \mathrm{~km}$ in March (Figure 13c). The latitude of AE and CE shows opposite patterns in the Banda Sea (Figure 13d). AEs tend to seat in the southern Banda Sea during austral winter and in the northern Banda Sea during austral summer. Meanwhile, CEs prefer to populate in the southern Banda Sea for austral summer and in the northern Banda Sea for austral winter. More energetic AEs exist 
during austral summer with a peak value of $736 \mathrm{~cm}^{2} / \mathrm{s}^{2}$, and the mean EKE of AE reaches the minimum of $335.2 \mathrm{~cm}^{2} / \mathrm{s}^{2}$ in austral winter (Figure 13e). The seasonal cycle of mean EKE for CE is a bimodal curve with two peaks in February and June with corresponding values of $672.5 \mathrm{~cm}^{2} / \mathrm{s}^{2}$ and $585.6 \mathrm{~cm}^{2} / \mathrm{s}^{2}$, and two troughs in April and October with the values of $509.2 \mathrm{~cm}^{2} / \mathrm{s}^{2}$ and $488.5 \mathrm{~cm}^{2} / \mathrm{s}^{2}$, respectively (Figure 13e). No significant seasonal variability of mean relative vorticity for $\mathrm{CE}$ is observed, with the maximum of $9.5 \times 10^{-6} \mathrm{~s}^{-1}$ in March and the minimum of $8.0 \times 10^{-6} \mathrm{~s}^{-1}$ in October (Figure 13f). While the seasonal cycle of mean relative vorticity for AE displays a bimodal structure in the Banda Sea: two peaks exist in March and July with corresponding values of $9.4 \times 10^{-6} \mathrm{~s}^{-1}$ and $7.9 \times 10^{-6} \mathrm{~s}^{-1}$ and two troughs appear in June and September with values of $7.1 \times 10^{-6} \mathrm{~s}^{-1}$ and $6.9 \times 10^{-6} \mathrm{~s}^{-1}$, respectively (Figure 13f).

(a)

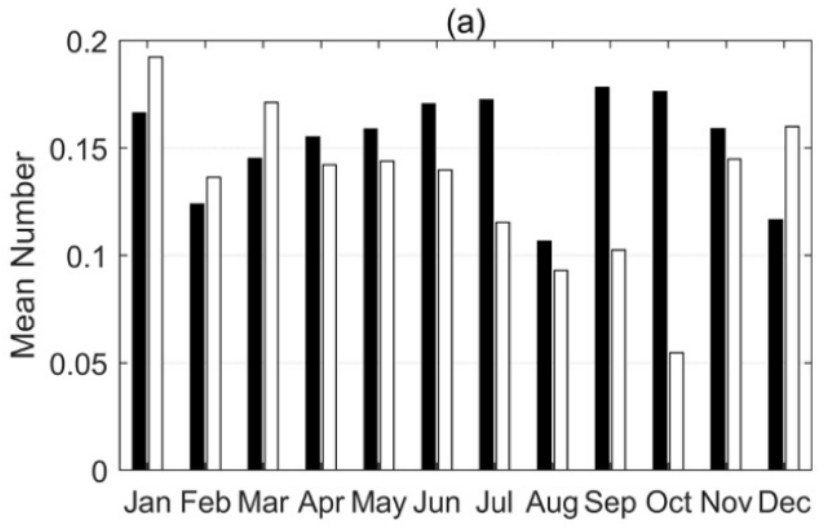

(c)

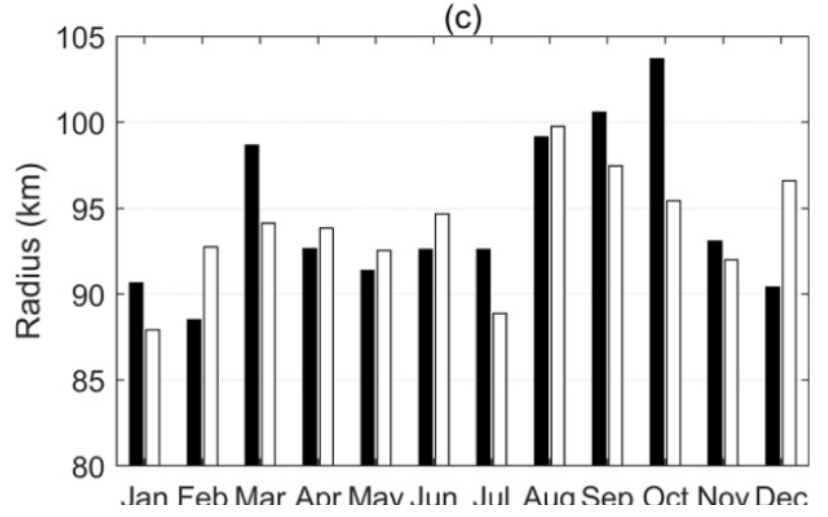

(b)

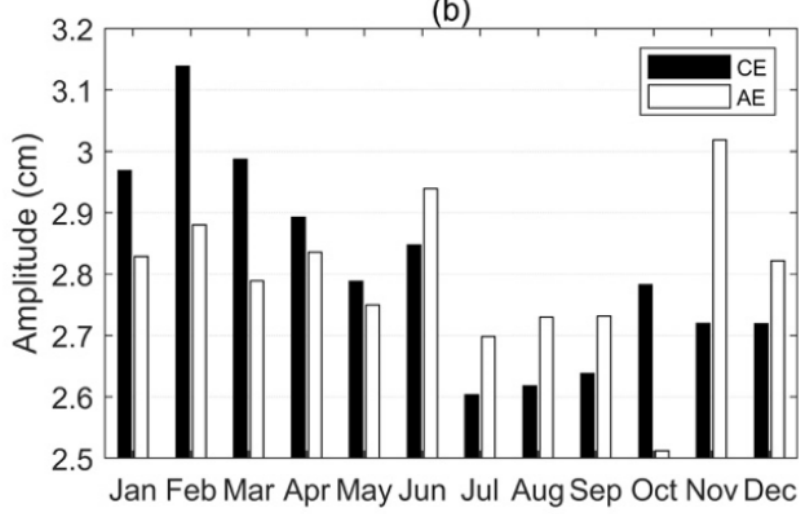

(d)

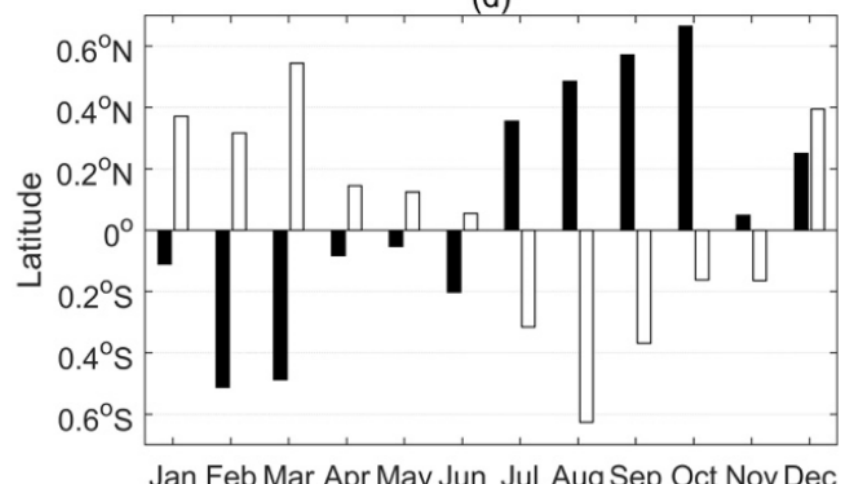

Figure 12. Seasonal cycles of eddy properties (black bars are for CE and white bars are for AE) in the Maluku Sea: (a) number of eddies, (b) amplitude, (c) radius and (d) central latitude. The units of amplitude and radius correspond to $\mathrm{cm}$ and $\mathrm{km}$.

\subsection{Eddy Nonlinearity}

The advective nonlinearity parameter is calculated to assess the degree of eddy nonlinearity in the Indonesian Seas. The advective nonlinearity parameter is a nondimensional ratio of $U / c$, where $U$ is the maximum rotation speed and $c$ is the propagation speed of each eddy [2]. The definition of $\mathrm{c}$ is shown in Section 3.2. Figure 14 displays the upper-tail histogram of $U / c$ for the Sulu Sea, Sulawesi Sea and Banda Sea. Most eddies in these three seas are nonlinear by this measure, among which $U / c$ exceeding 1 account for $89 \%$ $(88 \%), 100 \%(100 \%)$ and $94 \%(96 \%)$ for AE (CE) in the Sulu Sea, Sulawesi Sea and Banda Sea, respectively. Most highly nonlinear eddies are observed in the Sulawesi Sea, with $48 \%$ of the $U / c$ values exceeding 5 and $17 \%$ exceeding 10, as observed in major unstable and meandering currents of global ocean [2]. Fewer eddies with high nonlinearity are detected in the Sulu Sea and Banda Sea (Figure 14a,c), where the $U / c$ values above 10 is less than $10 \%$. The distributions of $U / c$ for eddies are more skewed to higher values for $\mathrm{AE}$ than for CE in the Sulu Sea, but the opposite is found in the Banda Sea. 

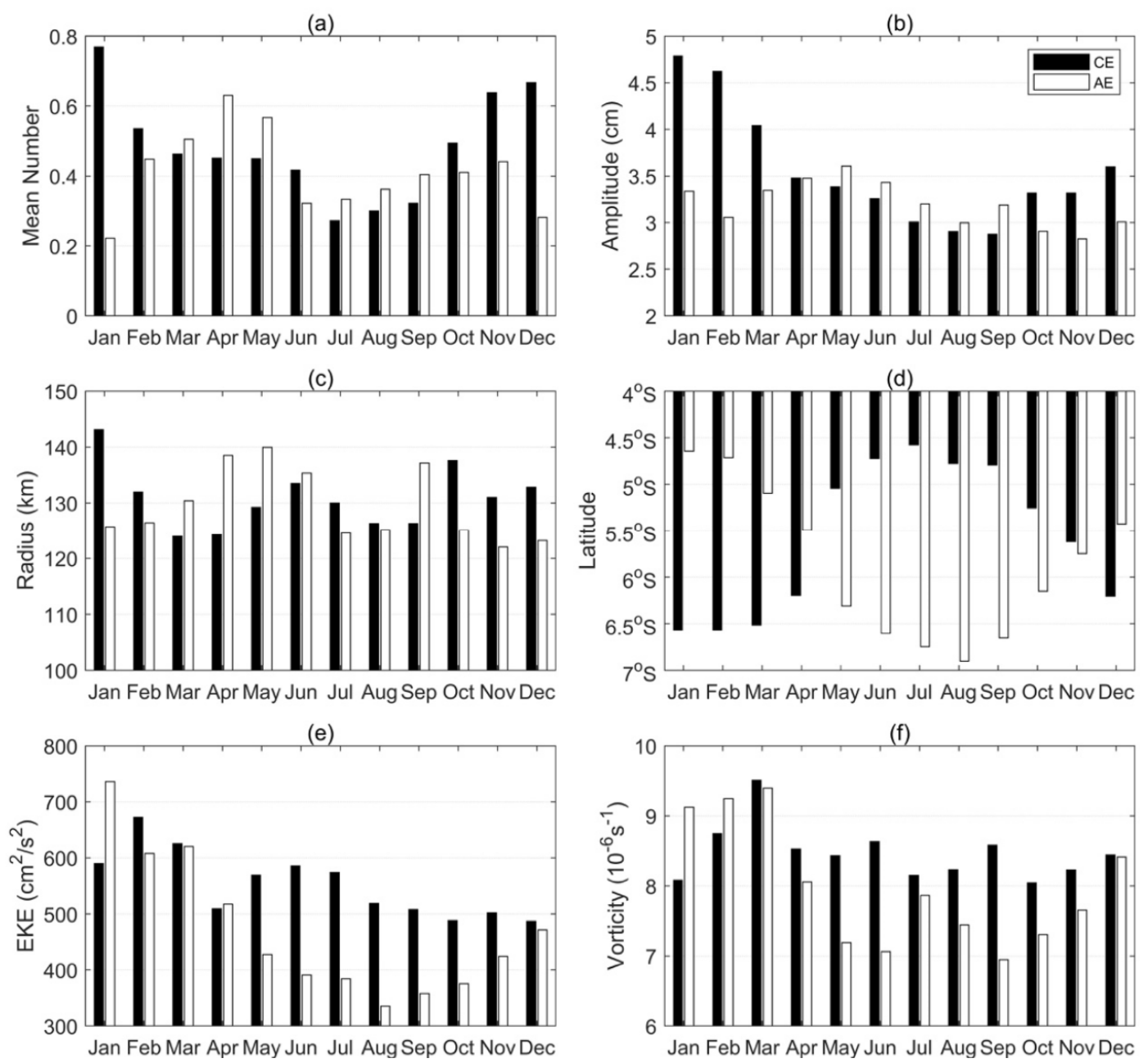

Figure 13. Seasonal cycles of eddy properties (black bars are for $\mathrm{CE}$ and white bars are for AE) in the Banda Sea: (a) number of eddies, (b) amplitude, (c) radius, (d) central latitude, (e) mean EKE and (f) mean vorticity. The units of amplitude, radius, mean EKE and mean vorticity correspond to $\mathrm{cm}, \mathrm{km}, \mathrm{cm}^{2} / \mathrm{s}^{2}$ and $10^{-6} \mathrm{~s}^{-1}$.
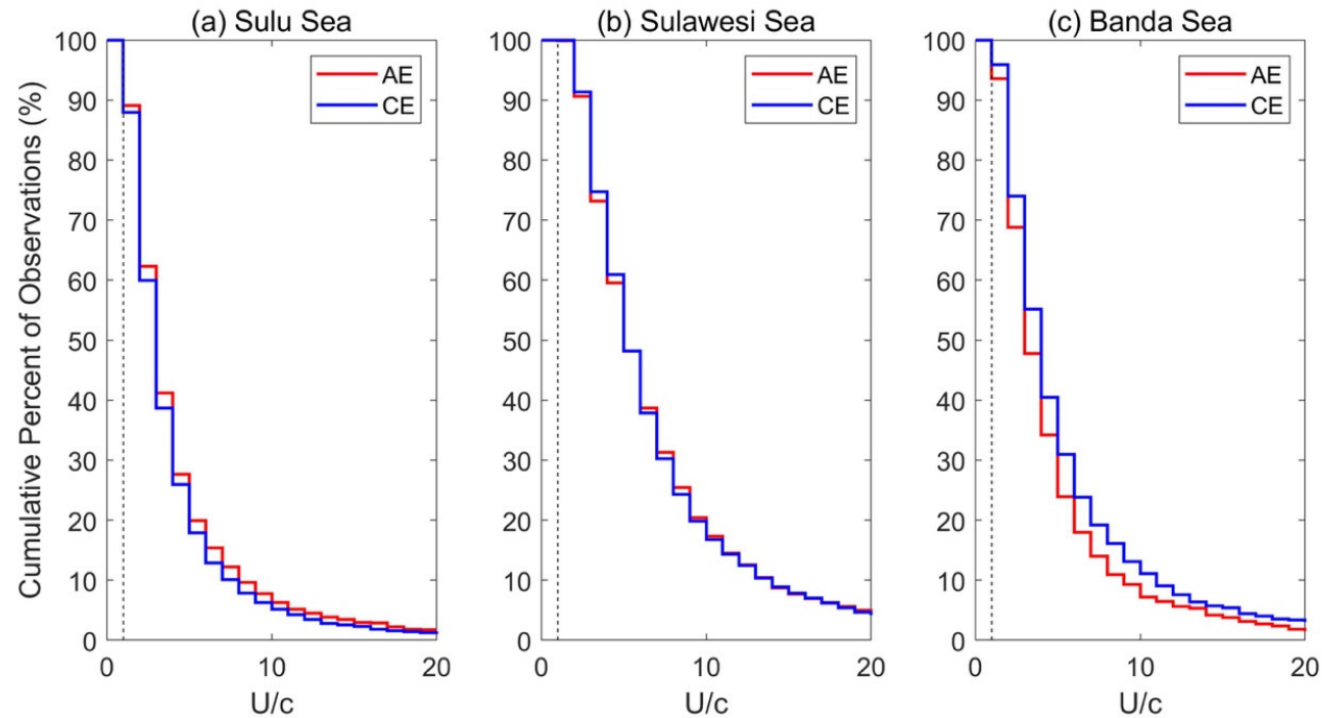

Figure 14. Upper-tail cumulative histograms of $U / c$ in the (a) Sulu Sea, (b) Sulawesi Sea and (c) Banda Sea. The red and blue lines in each panel correspond to AE and CE, respectively. Additionally, the vertical dotted lines in each panel indicate that the value of $U / c$ is equal to 1 . 


\section{Discussion}

To investigate the generation mechanism of eddies in the Indonesian Seas, we calculated the BTR, KHR and BCR, respectively, using BRAN outputs from 1994 to 2015. Due to the complex current patterns and the different spatial distribution of eddy genesis in each basin, we select four subregions in the Sulu Sea, Sulawesi Sea, Maluku Sea and Banda Sea (Figure 1, dashed boxes). These four subregions are defined in the Appendix A. We also find that BRAN can reasonably reproduce mesoscale eddies in the Indonesian Seas, and more details of evaluation refer to Appendix B. The seasonal cycles of volume integral BTR, KHR and BCR in each box are displayed in Figure 15. In these four regions, the volumetric integral BCR is positive throughout the year, which means EPE converts to EKE through baroclinic instability. Meanwhile, the volume integration of BTR for each box is positive in most seasons, except for some seasons in the Sulu Box and Maluku Box (Figure 15a,c). The weak negative BTR may result from inverse energy cascade from EKE to MKE [4,5], and the detailed discussions for this beyond the scope of present paper. However, the BTR almost dominates the energy conversion in the Sulawesi box throughout the year (Figure 15b), as in the Gulf Stream [4] and Kuroshio [5]. This result is similar to the conclusions of Yang et al. [33] that the EKE is governed by barotropic instability of mean flow. Compared with BTR and BCR, KHR are much smaller and make little net contribution to EKE in all four boxes. Therefore, barotropic and baroclinic instability dominate eddy generation in the Indonesian Seas. There are some seasonal variations of BTR and BCR, likely associated with the seasonal variations if the mean flow.
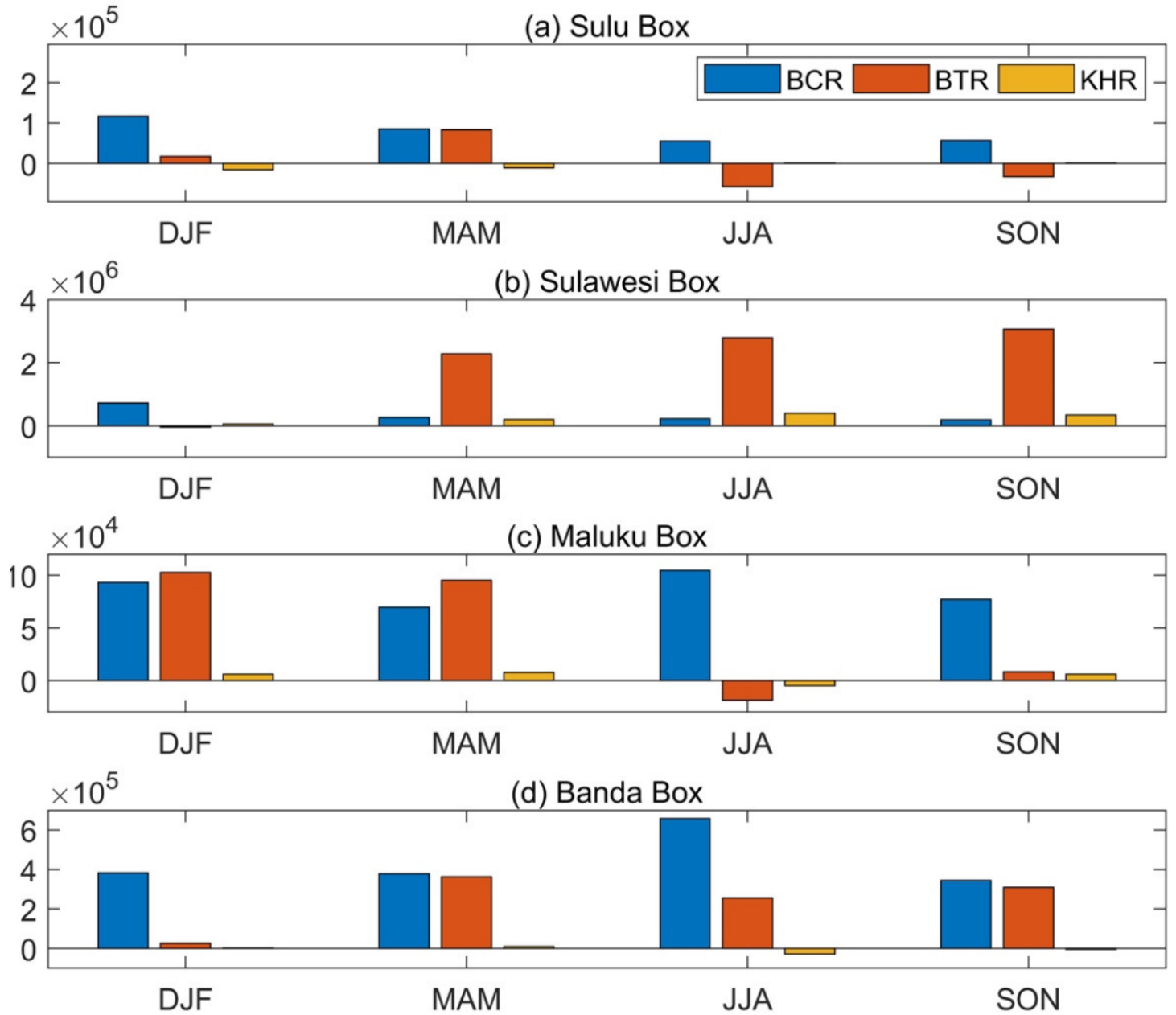

Figure 15. Seasonal variation of volume integral barotropic conversion rate (BTR), baroclinic conversion rate (BCR) and Kelvin-Helmholtz conversion rate (KHR) in the (a) Sulu Box, (b) Sulawesi Box, (c) Maluku Box and (d) Banda Box, respectively. The unit is $\mathrm{m}^{5} / \mathrm{s}^{3}$. 
To further determine which instability dominates for individual eddy generation over the 1994-2015 period, the monthly BTR and BCR integrated vertically in the upper $300 \mathrm{~m}$ are firstly calculated. Secondly, the corresponding values of BTR and BCR for each eddy genesis event were extracted according to its generation position and month. Thirdly, a comparison between BTR and BCR is performed to assess an eddy genesis event dominated by either barotropic instability $(B T R>B C R>0)$ or baroclinic instability $(\mathrm{BCR}>\mathrm{BTR}>0)$. Figure 16 presents the spatial distribution of the number of eddy genesis events dominated by barotropic and baroclinic instability. In the Sulu Sea, eddy genesis events dominated by barotropic instability account for $48 \%$ while those dominated by baroclinic instability are 35\% of total eddy generation. This is similar to He et al. [34], who concluded that the instability of mean flow is one of the major eddy generation mechanisms. Barotropic instability dominates eddy generation in the Sulawesi Sea with a percentage of $55 \%$, as in Yang et al [33], while the corresponding value of baroclinic dominance is $26 \%$ in the Sulawesi Sea. It is clear that barotropic instability is more frequent in the central Sulawesi Sea where the most intrusion of MC is located (Figure 16a), and eddy generation is dominated by baroclinic instability in the northern Sulawesi Sea (Figure 16b). In the Maluku Sea, $47 \%$ of eddy genesis events are dominated by baroclinic instability, while $43 \%$ are dominated by barotropic instability. Baroclinic instability in the Banda Sea dominates by $49 \%$ of eddy generation (Figure 16b). Additionally, the percentage of eddy generation dominated by barotropic instability is $40 \%$ in the Banda Sea (Figure 16a). For the Indonesian Seas as a whole, barotropic instability dominates the eddy generation with a percentage of $49 \%$, which is higher than that dominated by baroclinic instability with a percentage of $35 \%$. This is similar to the previous conclusions that barotropic instability is the dominant mechanisms in EKE generation along intense boundary currents, such as the Gulf Stream and Kuroshio, while baroclinic instability dominates in the broader open ocean [3-5]. A total of $16 \%$ of eddies in the Indonesian Seas are not dominated by either barotropic or baroclinic instability, so that costal Kelvin waves and complex topography may also affect eddy generation [57].

In our analysis, eddies with amplitude less than $2 \mathrm{~cm}$ are excluded according to the fact that the accuracy of gridded SLA product provided by AVISO is about $2 \mathrm{~cm}[15,51]$. Generally, the variability of eddy amplitude during its lifetime undergoes growing stage, mature stage and decaying stage [15,19]. Inevitably, the eddy amplitudes less than $2 \mathrm{~cm}$ exist in the beginning and end of eddy lifespan, which are below the resolving ability of altimeter data [2,51]. There are two possible effects: one is underestimate of eddy lifespan; the other is that locations of eddy generation and decay tracked by eddy tracking algorithm may have some offset. However, our results in the Sulu Sea are similar to that of He et al. [34], especially with same spatial and temporal variability for eddy properties. The eddy amplitudes dramatically increase and decrease in growing stage and decaying stage, respectively, which account for less than $20 \%$ of the eddy lifespan $[15,19]$. Besides, the propagation speed of eddies in the Indonesian Seas is really small, with a mean value below $6 \mathrm{~cm} / \mathrm{s}$ and identified eddies whose lifespan are less 30 days account for more than $80 \%$. Thus, there is likely no significant difference between the positions detected by eddy tracking algorithm and the actual positions for eddy generation and decay in the region.

Additionally, the reader should be reminded that a free running model cannot reproduce real particular eddy events, while data assimilation inevitably interferes the dynamical or energy balance [40]. The new version of BRAN have used globally balanced forcing and low update cycle of assimilation (4 days) which improved the dynamic imbalance in the previous version [40]. Zhang et al. [12] have proved that BRAN performs well for the instability analysis and the robustness of their conclusions is further proved by a free running model, the eddy-resolving OGCM for the Earth Simulator (OFES). Besides, the magnitude of BTR averaged vertically in the Sulawesi Sea using BRAN outputs in this study is equal to the magnitude, $10^{-3} \mathrm{~cm}^{2} / \mathrm{s}^{3}$, estimated based on OFES outputs [33]. Although the detailed assessment of the difference of EKE budget analysis between BRAN and a free running model beyond the scope of this paper, future studies about this assessment are on the way. 
This paper reports the statistical characteristics and spatiotemporal variations for the eddies across the whole Indonesian Seas for the first time. We believe that our results can be used to assess the performance of numerical models in terms of reproducing mesoscale eddies and to improve local ocean forecasts. Moreover, the significant meridional migrations and the high nonlinearity of eddies revealed in this study indicate considerable eddy transports of heat and salt $[29,31]$, which will be the focus of our ongoing research. In addition, because eddies play a key role in the circulation of semi-closed and enclosed basins [34,47], our conclusions can also be used for the further investigations of eddyITF interaction.
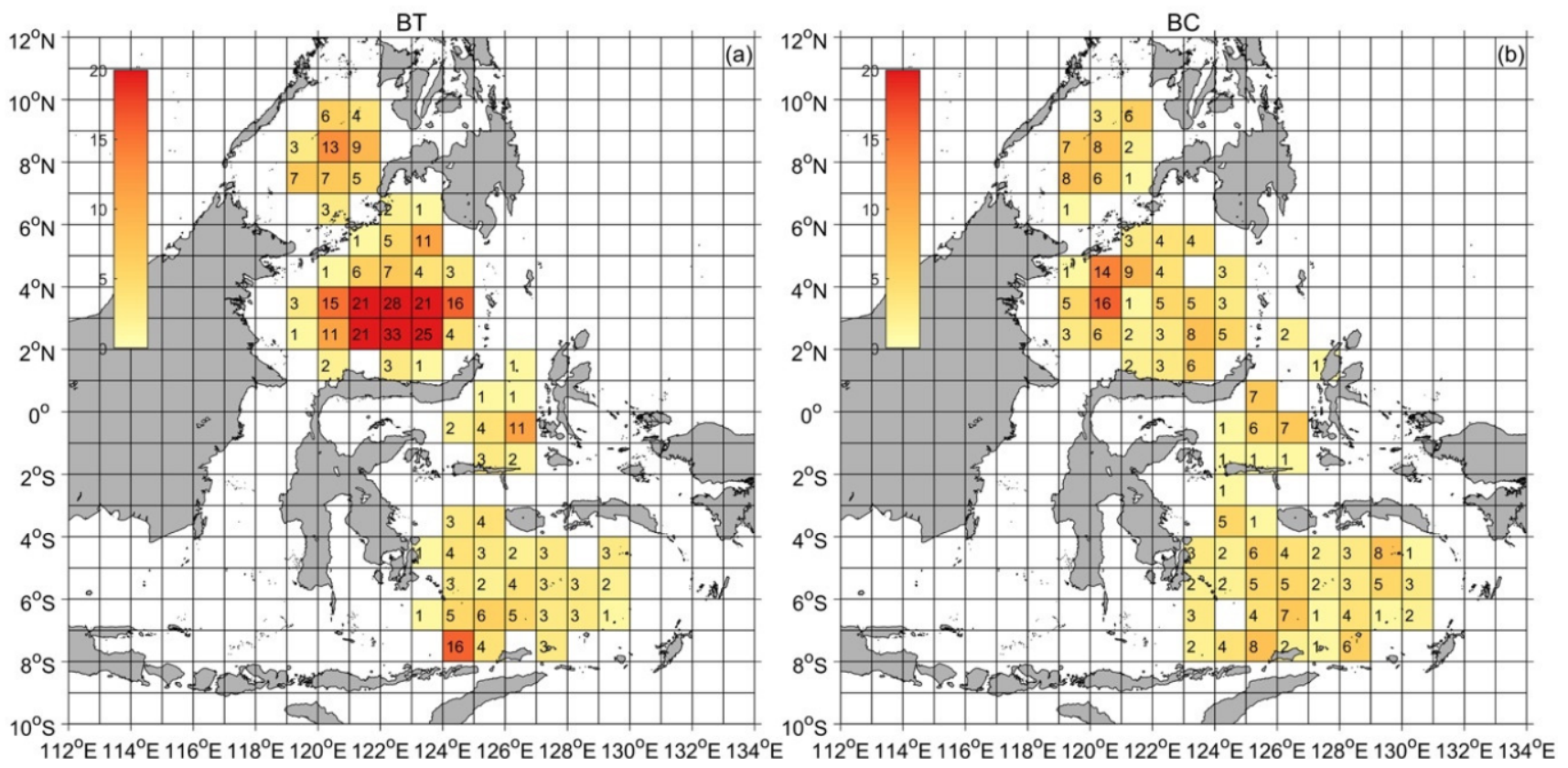

Figure 16. Spatial distribution of eddy genesis events dominated by (a) barotropic instability and (b) baroclinic instability. The unit is the number of eddy genesis events.

\section{Conclusions}

In this study, we provided a detailed description for both spatial and temporal variability of eddies in the Indonesian Seas using altimeter data and discussed their generation mechanisms using high-resolution model outputs. A total of $469 \mathrm{AE}$ tracks and $500 \mathrm{CE}$ tracks were identified from January 1993 to December 2018. Most of eddies in the Indonesian Seas are short-lived (below 30 days) with a percentage of $73 \%(84 \%), 85 \%(86 \%), 100 \%$ $(94 \%)$ and $86 \%(80 \%)$ for AE (CE) in the Sulu Sea, Sulawesi Sea, Maluku Sea and Banda Sea, respectively. There is no geographical preference for $\mathrm{AE}$ and $\mathrm{CE}$ in above four basins. For the mechanisms of eddy generation, barotropic instability dominates over baroclinic instability in the Sulu Sea and Sulawesi Sea, while baroclinic instability is slightly more important in the Maluku Sea and Banda Sea. Most energetic eddies are observed in the Sulawesi Sea and Seram Sea. The spatial distribution of eddy properties shows high inhomogeneity with typical amplitudes and radiuses of 2-6 cm and 50-160 km, respectively. Because of the intrusion of MC in the Sulawesi Sea, CE has larger amplitude and radius than AE. Limited by basin scale, the eddies in the Maluku Sea show smaller amplitude and radius.

The climatological properties of eddies in the Indonesian Seas exhibit different seasonal variations between AE and CE not only in each basin but also among four major basins. In the Sulu Sea, AEs prevail with relatively large amplitude and radius in the boreal summer, while CEs display an opposite seasonal variability. The mean number, amplitude and radius of eddies in the Sulawesi Sea present bimodal structure in seasonal cycles, with opposite phases between AE and CE. In the Banda Sea, the seasonal cycle of AE properties, 
including mean number, amplitude and radius, shows a bimodal structure, while CEs are more abundant with larger amplitude during austral summer than the other three seasons. There is no consistent tendency in the seasonal cycle of the mean number, amplitude and radius for both $\mathrm{AE}$ and $\mathrm{CE}$ in the Maluku Sea. It is interesting that every basin in the Indonesian Seas displays a reversal meridional distribution of eddy polarity with season. Nevertheless, our results only focused on a comprehensive description of eddy properties at the surface due to the limitation of altimeter data, future studies should explore the three-dimensional structure of eddies in the Indonesian Seas and their contributions to the ITF dynamics and thermodynamics.

Supplementary Materials: The following are available online at https:/ www.mdpi.com/2072-4 292/13/5/1017/s1, Figure S1: Spatial distribution of amplitude and radius of AE and CE over the 1994-2015 period from BRAN. Figure S2: Spatial distribution of mean EKE and mean relative vorticity of AE and CE over the 1994-2015 period from BRAN. Figure S3: Seasonal cycles of eddy properties in the Sulu Sea over the 1994-2015 period from BRAN. Figure S4: Seasonal cycles of eddy properties in the Sulawesi Sea over the 1994-2015 period from BRAN. Figure S5: Seasonal cycle of eddy properties in the Banda Sea over the 1994-2015 period from BRAN.

Author Contributions: Conceptualization, Z.H., Z.X. and M.F.; methodology, Z.H., M.F. and Q.L.; writing-original draft presentation, Z.H.; writing-review and editing, Z.X., M.F., B.Y. and Z.H. All authors have read and agreed to the published version of the manuscript.

Funding: This study was jointly supported by the Strategic Priority Research Program of Chinese Academy of Sciences (XDB42000000, XDA11010204), the National Natural Science Foundation of China (91858103, 92058202), CAS Key Research Program of Frontier Sciences (QYZDB-SSW-DQC024), the National Key Research and Development Program of China (2017YFA0604102, 2016YFC1402705), Key Deployment Project of Centre for Ocean Mega-Research of Science,Chinese Academy of Sciences (COMS2020Q07), the project jointly funded by the CAS and CSIRO (133244KYSB20190031).

Institutional Review Board Statement: Not applicable.

Informed Consent Statement: Not applicable.

Data Availability Statement: The datasets for this study are publicly available. The altimetry sea surface height, sea level anomalies and geostrophic velocities are provided by Archiving, Validation, and Interpolation of Satellite Oceanographic (AVISO) data and distributed by the Copernicus Marine Environment Monitoring Service (CMEMS) via https: / / marine.copernicus.eu/ (accessed on 4 March 2021). The Bluelink ReANalysis data is provided by National Computational Infrastructure thredds server of Australia via https:/ / www.nci.org.au/ (accessed on 4 March 2021).

Acknowledgments: This research is partly supported by the Centre for Southern Hemisphere Oceans Research (CSHOR), which is a joint initiative between the Qingdao National Laboratory for Marine Science and Technology (QNLM), CSIRO, University of New South Wales and University of Tasmania. We would like to thank the four anonymous reviewers whose constructive comments have significantly improved the manuscript.

Conflicts of Interest: The authors declare no conflict of interest. The funders had no role in the design of the study; in the collection, analyses, or interpretation of data; in the writing of the manuscript, or in the decision to publish the results.

\section{Appendix A}

The seasonal cycle of mean circulation averaged above $300 \mathrm{~m}$ in the Indonesian Seas simulated by BRAN is shown in Figure A1. In the Sulu Sea, a cyclonic circulation prevails in boreal winter while an anticyclonic circulation exists in boreal summer, which resulted from seasonal local wind forcing and outflow via the Sibutu Passage [45]. MC intrudes in the Sulawesi Sea as a cyclonic loop structure through the whole year with a weaker intrusion in January (Figure A1a). There is an anticyclonic sub-basin scale circulation in the north of $4^{\circ} \mathrm{N}$ in the Sulawesi Sea. The other intrusion of MC concentrates in the northern Maluku Sea, while relatively weak northward flow exists in the central and southern Maluku Sea. In the Banda Sea, the currents in the upper circulation flows eastward during 
the northwesterly monsoon while flowing westward with relatively weak strength during the southeasterly monsoon, as also simulated by Zhu et al. [58].

Based on the complex upper-ocean current patterns, we selected four subregions with more frequent eddy genesis events. The detailed range of the four rectangular subregions, respectively, in the Sulu Sea, Sulawesi Sea, Maluku Sea and Banda Sea (Figure A1) are as follows:

1. Sulu Box: $119^{\circ} \mathrm{E} \sim 123^{\circ} \mathrm{E}, 7^{\circ} \mathrm{N} \sim 10^{\circ} \mathrm{N}$;

2. Sulawesi Box: $119^{\circ} \mathrm{E} \sim 125^{\circ} \mathrm{E}, 2^{\circ} \mathrm{N} \sim 5^{\circ} \mathrm{N}$;

3. Maluku Box: $125^{\circ} \mathrm{E} \sim 127^{\circ} \mathrm{E}, 2^{\circ} \mathrm{S} \sim 1^{\circ} \mathrm{N}$;

4. Banda Box: $122^{\circ} \mathrm{E} \sim 131^{\circ} \mathrm{E}, 4^{\circ} \mathrm{S} \sim 7.5^{\circ} \mathrm{S}$.
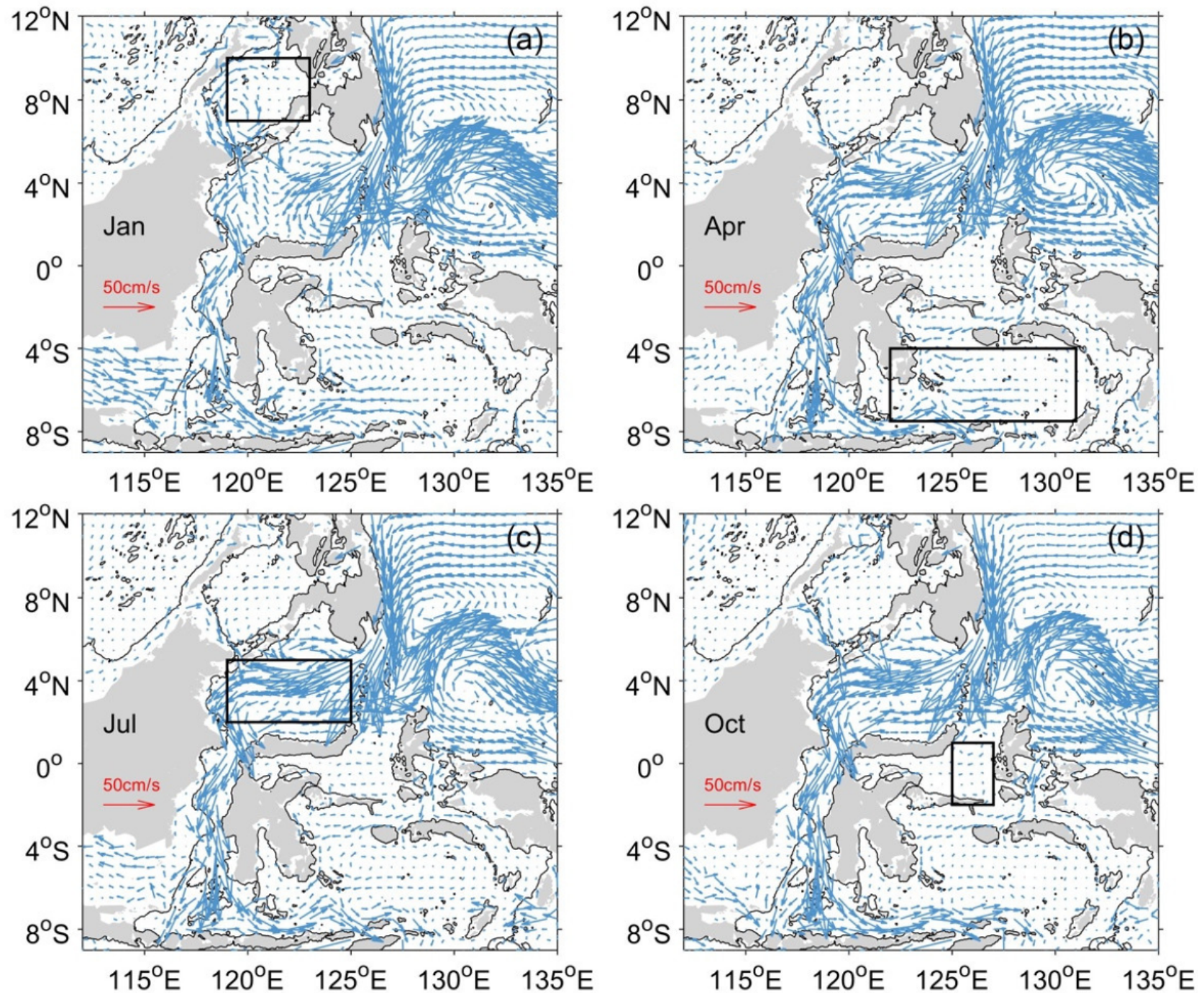

Figure A1. Mean currents (blue arrows) averaged above $300 \mathrm{~m}$ depth in (a) January, (b) April, (c) July and (d) October from the BRAN outputs. The solid line is the $200 \mathrm{~m}$ isobath. Location of the four subregions in the Sulu Sea, Sulawesi Sea, Maluku Sea and Banda Sea. The boxes are (a) Sulu Box, (b) Banda Box, (c) Sulawesi Box and (d) Maluku Box, respectively. For regions shallower than $300 \mathrm{~m}$, the average is for the whole water column.

\section{Appendix B}

To evaluate whether BRAN reproduces realistic mesoscale eddies in the Sulu Sea, Sulawesi Sea, Maluku Sea and Banda Sea, we also detect eddies from the daily SLA snapshots of BRAN over the 1994-2015 period. The eddies with lifetime longer than 10 days and amplitude larger than $2 \mathrm{~cm}$ are considered for the analysis. The spatial distributions of eddy genesis and decay events from AVISO and BRAN over the 1994-2015 period are show in Figure A2. A total of 843 and 649 eddy tracks are detected from AVISO 
and BRAN over this period, respectively. The proportion of eddy tracks are $14 \%(22 \%)$, $53 \%(50 \%), 7 \%(1 \%)$ and $26 \%(27 \%)$ in the Sulu Sea, Sulawesi Sea, Maluku Sea and Banda Sea, respectively. The distributions of both eddy generation and eddy decay share a similar pattern between AVISO and BRAN in the Sulu Sea, Sulawesi Sea and Banda Sea. However, the numbers of eddy tracks in these four seas from BRAN are smaller than those from AVISO. This may result from the difference of data resolution, as is also found in the Subtropical Countercurrent regions from OFES outputs [59].
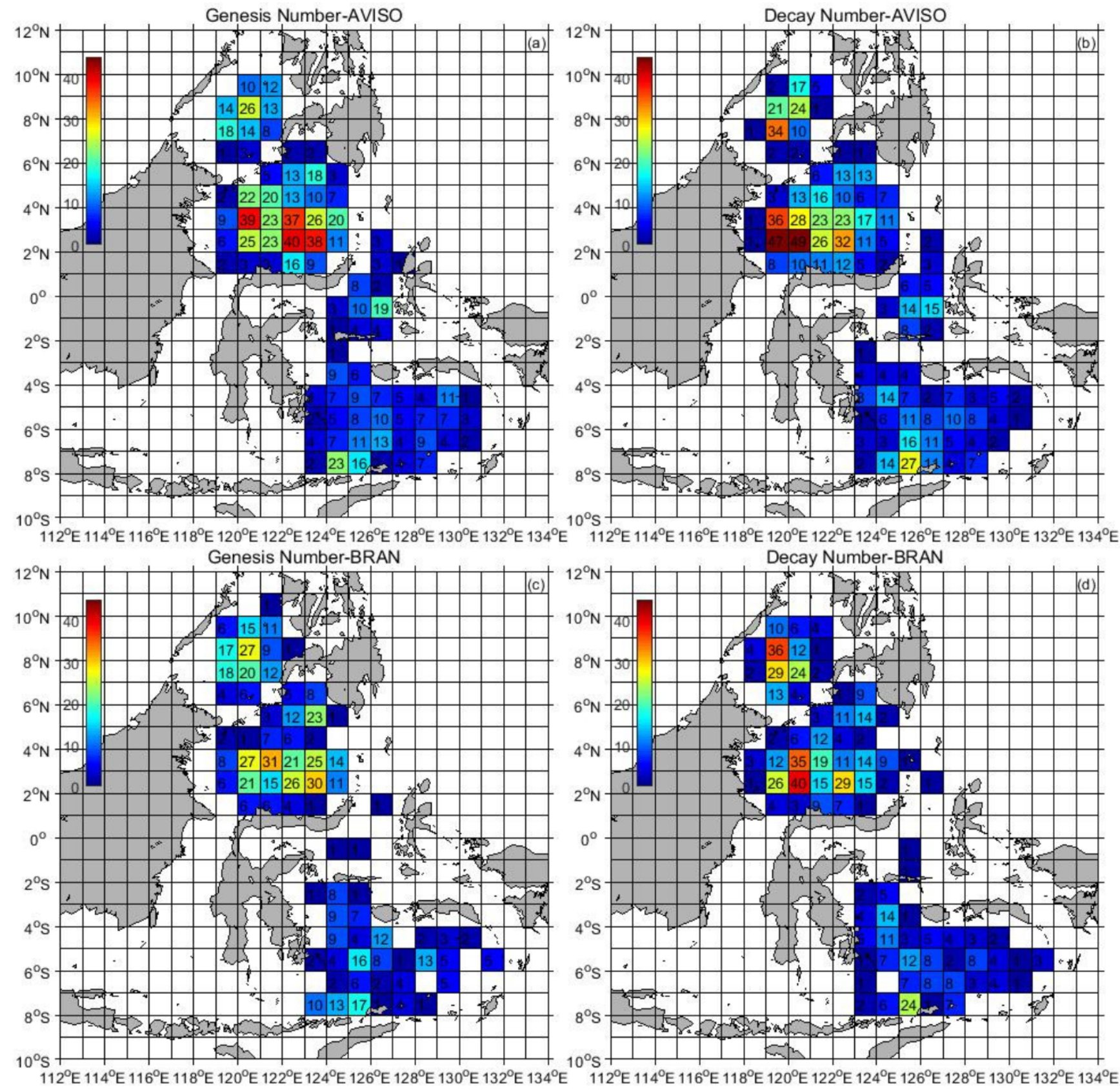

Figure A2. Spatial distribution of eddy genesis and decay events over the 1994-2015 period from AVISO (the first row) and BRAN (the second row): (a) genesis number from AVISO, (b) decay number from AVISO, (c) genesis number from BRAN and (d) decay number from BRAN. The unit is the number of events.

To further demonstrate the performance of BRAN in terms of mesoscale eddies, the comparison for the trajectories of eddies detected from AVISO and BRAN are performed. We find that BRAN can reproduce the realistic trajectories of mesoscale eddies in the regions we are interested, with the similar pathways and generation locations. Some examples 
in the Sulu Sea, Sulawesi Sea and Banda Sea are shown in Figure A3. Besides, BRAN can reasonably capture the spatial and temporal variations of eddy properties in the Sulu Sea, Sulawesi Sea and Banda Sea (see Supplementary Materials Figures S1-S5 for more details). Thus, we believe that BRAN is a credible reanalysis dataset to investigate the eddy generation mechanisms.
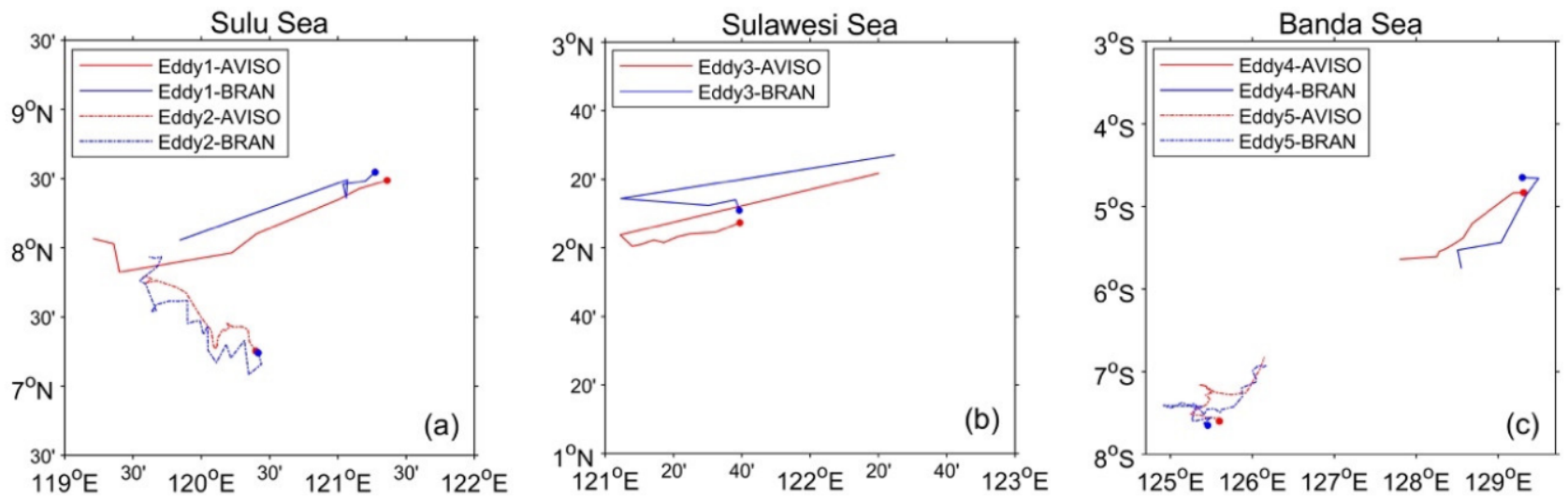

Figure A3. Trajectories of same eddies from AVISO and BRAN in the (a) Sulu Sea, (b) Sulawesi Sea and (c) Banda Sea. The red line represents the trajectory of an eddy observed in AVISO. The blue line represents the trajectory of the corresponding eddy simulated by BRAN. The dots represent the initial locations of each trajectory.

\section{References}

1. Fu, L.L.; Chelton, D.B.; Le Traon, P.Y.; Morrow, R. Eddy dynamics from satellite altimetry. Oceanography 2010, 23, 15-25. [CrossRef]

2. Chelton, D.B.; Schlax, M.G.; Samelson, R.M. Global observations of nonlinear mesoscale eddies. Prog. Oceanogr. 2011, 91, 167-216. [CrossRef]

3. Von Storch, J.S.; Eden, C.; Fast, I.; Haak, H.; Hernández-Deckers, D.; Maier-Reimer, E.; Marotzke, J.; Stammer, D. An estimate of the Lorenz energy cycle for the World Ocean based on the 1/10STORM/NCEP simulation. J. Phys. Oceanogr. 2012, 42, $2185-2205$. [CrossRef]

4. Kang, D.; Curchitser, E.N. Energetics of eddy-mean flow interactions in the gulf stream region. J. Phys. Oceanogr. 2015, 45, 1103-1120. [CrossRef]

5. Yan, X.; Kang, D.; Curchitser, E.N.; Pang, C. Energetics of eddy-mean flow interactions along the western boundary currents in the North Pacific. J. Phys. Oceanogr. 2019, 49, 789-810. [CrossRef]

6. Feng, M.; Wijffels, S.; Godfrey, S.; Meyers, G. Do eddies play a role in the momentum balance of the Leeuwin Current? J. Phys. Oceanogr. 2005, 35, 964-975. [CrossRef]

7. Zheng, Z.W.; Ho, C.R.; Kuo, N.J. Mechanism of weakening of west Luzon eddy during La Niña years. Geophys. Res. Lett. 2007, 34, 1-5. [CrossRef]

8. Cheng, Y.H.; Ho, C.R.; Zheng, Q.; Kuo, N.J. Statistical characteristics of mesoscale eddies in the north pacific derived from satellite altimetry. Remote Sens. 2014, 6, 5164-5183. [CrossRef]

9. Pegliasco, C.; Chaigneau, A.; Morrow, R. Main eddy vertical structures observed in the four major Eastern Boundary Upwelling Systems. J. Geophys. Res. Oceans 2015, 120, 6008-6033. [CrossRef]

10. Dong, D.; Brandt, P.; Chang, P.; Schütte, F.; Yang, X.; Yan, J.; Zeng, J. Mesoscale Eddies in the Northwestern Pacific Ocean: Three-Dimensional Eddy Structures and Heat/Salt Transports. J. Geophys. Res. Oceans 2017, 122, 9795-9813. [CrossRef]

11. Cheng, Y.H.; Ho, C.R.; Zheng, Q.; Qiu, B.; Hu, J.; Kuo, N.J. Statistical features of eddies approaching the Kuroshio east of Taiwan Island and Luzon Island. J. Oceanogr. 2017, 73, 427-438. [CrossRef]

12. Zhang, N.; Liu, G.; Liu, Q.; Zheng, S.; Perrie, W. Spatiotemporal Variations of Mesoscale Eddies in the Southeast Indian Ocean. J. Geophys. Res. Oceans 2020, 125, 1-18. [CrossRef]

13. Shen, D.; Li, X.; Wang, J.; Bao, S.; Pietrafesa, L.J. Dynamical ocean responses to Typhoon Malakas (2016) in the vicinity of Taiwan. J. Geophys. Res. Oceans 2020. [CrossRef]

14. Stammer, D. On eddy characteristics, eddy transports, and mean flow properties. J. Phys. Oceanogr. 1998, 28, 727-739. [CrossRef]

15. Chen, G.; Han, G. Contrasting Short-Lived With Long-Lived Mesoscale Eddies in the Global Ocean. J. Geophys. Res. Oceans 2019, 124, 3149-3167. [CrossRef]

16. Laxenaire, R.; Speich, S.; Blanke, B.; Chaigneau, A.; Pegliasco, C.; Stegner, A. Anticyclonic Eddies Connecting the Western Boundaries of Indian and Atlantic Oceans. J. Geophys. Res. Oceans 2018, 123, 7651-7677. [CrossRef]

17. Faghmous, J.H.; Frenger, I.; Yao, Y.; Warmka, R.; Lindell, A.; Kumar, V. A daily global mesoscale ocean eddy dataset from satellite altimetry. Sci. Data 2015, 2, 1-16. [CrossRef] 
18. Chaigneau, A.; Gizolme, A.; Grados, C. Mesoscale eddies off Peru in altimeter records: Identification algorithms and eddy spatio-temporal patterns. Prog. Oceanogr. 2008, 79, 106-119. [CrossRef]

19. Aguedjou, H.M.A.; Dadou, I.; Chaigneau, A.; Morel, Y.; Alory, G. Eddies in the Tropical Atlantic Ocean and Their Seasonal Variability. Geophys. Res. Lett. 2019, 46, 12156-12164. [CrossRef]

20. Feng, M.; Zhang, N.; Liu, Q.; Wijffels, S. The Indonesian throughflow, its variability and centennial change. Geosci. Lett. 2018, 5. [CrossRef]

21. Sprintall, J.; Gordon, A.L.; Wijffels, S.E.; Feng, M.; Hu, S.; Koch-Larrouy, A.; Phillips, H.; Nugroho, D.; Napitu, A.; Pujiana, K.; et al. Detecting change in the Indonesian seas. Front. Mar. Sci. 2019, 6. [CrossRef]

22. Lukas, R.; Firing, E.; Hacker, P.; Richardson, P.L.; Collins, C.A.; Fine, R.; Gammon, R. Observations of the Mindanao Current during the western equatorial Pacific Ocean circulation study. J. Geophys. Res. 1991, 96, 7089-7104. [CrossRef]

23. Yuan, D.; Li, X.; Wang, Z.; Li, Y.; Wang, J.; Yang, Y.; Hu, X.; Tan, S.; Zhou, H.; Wardana, A.K.; et al. Observed transport variations in the Maluku Channel of the Indonesian seas associated with western boundary current changes. J. Phys. Oceanogr. 2018, 48, 1803-1813. [CrossRef]

24. Gordon, A.L.; Napitu, A.; Huber, B.A.; Gruenburg, L.K.; Pujiana, K.; Agustiadi, T.; Kuswardani, A.; Mbay, N.; Setiawan, A. Makassar Strait Throughflow Seasonal and Interannual Variability: An Overview. J. Geophys. Res. Oceans 2019, 124, $3724-3736$. [CrossRef]

25. Van Aken, H.M.; Brodjonegoro, I.S.; Jaya, I. The deep-water motion through the Lifamatola Passage and its contribution to the Indonesian throughflow. Deep. Res. Part I Oceanogr. Res. Pap. 2009, 56, 1203-1216. [CrossRef]

26. Fang, G.; Susanto, R.D.; Wirasantosa, S.; Qiao, F.; Supangat, A.; Fan, B.; Wei, Z.; Sulistiyo, B.; Li, S. Volume, heat, and freshwater transports from the South China Sea to Indonesian seas in the boreal winter of 2007-2008. J. Geophys. Res. Oceans 2010, 115, 1-11. [CrossRef]

27. Gordon, A.L.; Huber, B.A.; Metzger, E.J.; Susanto, R.D.; Hurlburt, H.E.; Adi, T.R. South China Sea throughflow impact on the Indonesian throughflow. Geophys. Res. Lett. 2012, 39, 1-7. [CrossRef]

28. Qiu, B.; Mao, M.; Kashino, Y. Intraseasonal variability in the Indo-Pacific throughflow and the regions surrounding the Indonesian Seas. J. Phys. Oceanogr. 1999, 29, 1599-1618. [CrossRef]

29. Masumoto, Y.; Kagimoto, T.; Yoshida, M.; Fukuda, M.; Hirose, N.; Yamagata, T. Intraseasonal eddies in the Sulawesi Sea simulated in an ocean general circulation model. Geophys. Res. Lett. 2001, 28, 1631-1634. [CrossRef]

30. Kashino, Y.; Watanabe, H.; Herunadi, B.; Aoyama, M.; Hartoyo, D. Current variability at the Pacific entrance of the Indonesian Throughflow. J. Geophys. Res. Oceans 1999, 104, 11021-11035. [CrossRef]

31. Chen, X.; Qiu, B.; Chen, S.; Cheng, X.; Qi, Y. Interannual Modulations of the 50-Day Oscillations in the Celebes Sea: Dynamics and Impact. J. Geophys. Res. Oceans 2018, 123, 4666-4679. [CrossRef]

32. Kartadikaria, A.R.; Miyazawa, Y.; Nadaoka, K.; Watanabe, A. Existence of eddies at crossroad of the Indonesian seas. Ocean Dyn. 2012, 62, 31-44. [CrossRef]

33. Yang, C.; Chen, X.; Cheng, X.; Qiu, B. Annual versus semi-annual eddy kinetic energy variability in the Celebes Sea. J. Oceanogr. 2020, 76, 401-418. [CrossRef]

34. He, Y.; Feng, M.; Xie, J.; Liu, J.; Chen, Z.; Xu, J.; Fang, W.; Cai, S. Spatiotemporal Variations of Mesoscale Eddies in the Sulu Sea. J. Geophys. Res. Oceans 2017, 122, 7867-7879. [CrossRef]

35. Liu, Y.; Chen, G.; Sun, M.; Liu, S.; Tian, F. A parallel SLA-based algorithm for global mesoscale eddy identification. J. Atmos. Oceans Technol. 2016, 33, 2743-2754. [CrossRef]

36. Gulakaram, V.S.; Vissa, N.K.; Bhaskaran, P.K. Characteristics and vertical structure of oceanic mesoscale eddies in the Bay of Bengal. Dyn. Atmos. Oceans 2020, 89, 101131. [CrossRef]

37. Lagerloef, G.S.E.; Mitchum, G.T.; Lukas, R.B.; Niiler, P.P. Tropical Pacific near-surface currents estimated from altimeter, wind, and drifter data. J. Geophys. Res. Oceans 1999, 104, 23313-23326. [CrossRef]

38. Arbic, B.K.; Scott, R.B.; Chelton, D.B.; Richman, J.G.; Shriver, J.F. Effects of stencil width on surface ocean geostrophic velocity and vorticity estimation from gridded satellite altimeter data. J. Geophys. Res. Oceans 2012, 117, 1-18. [CrossRef]

39. Yuan, D.; Han, W.; Hu, D. Anti-cyclonic eddies northwest of Luzon in summer-fall observed by satellite altimeters. Geophys. Res. Lett. 2007, 34, 1-6. [CrossRef]

40. Oke, P.R.; Sakov, P.; Cahill, M.L.; Dunn, J.R.; Fiedler, R.; Griffin, D.A.; Mansbridge, J.V.; Ridgway, K.R.; Schiller, A. Towards a dynamically balanced eddy-resolving ocean reanalysis: BRAN3. Ocean Model. 2013, 67, 52-70. [CrossRef]

41. Schiller, A.; Oke, P.R.; Brassington, G.; Entel, M.; Fiedler, R.; Griffin, D.A.; Mansbridge, J.V. Eddy-resolving ocean circulation in the Asian-Australian region inferred from an ocean reanalysis effort. Prog. Oceanogr. 2008, 76, 334-365. [CrossRef]

42. He, Z.; Feng, M.; Wang, D.; Slawinski, D. Contribution of the Karimata Strait transport to the Indonesian Throughflow as seen from a data assimilation model. Cont. Shelf Res. 2015, 92, 16-22. [CrossRef]

43. Feng, M.; Benthuysen, J.; Zhang, N.; Slawinski, D. Freshening anomalies in the Indonesian throughflow and impacts on the Leeuwin Current during 2010-2011. Geophys. Res. Lett. 2015, 42, 8555-8562. [CrossRef]

44. Chu, P.C.; Edmons, N.L.; Fan, C. Dynamical mechanisms for the South China Sea seasonal circulation and thermohaline variabilities. J. Phys. Oceanogr. 1999, 29, 2971-2989. [CrossRef]

45. Cai, S.; He, Y.; Wang, S.; Long, X. Seasonal upper circulation in the Sulu Sea from satellite altimetry data and a numerical model. J. Geophys. Res. Oceans 2009, 114, 1-14. [CrossRef] 
46. Chelton, D.B.; Schlax, M.G.; Samelson, R.M.; de Szoeke, R.A. Global observations of large oceanic eddies. Geophys. Res. Lett. 2007, 34, 1-5. [CrossRef]

47. Zhan, P.; Subramanian, A.C.; Yao, F.; Hoteit, I. Eddies in the Red Sea: A statistical and dynamical study. J. Geophys. Res. Oceans 2014, 119, 3909-3925. [CrossRef]

48. Nencioli, F.; Dong, C.; Dickey, T.; Washburn, L.; Mcwilliams, J.C. A vector geometry-based eddy detection algorithm and its application to a high-resolution numerical model product and high-frequency radar surface velocities in the Southern California Bight. J. Atmos. Oceans Technol. 2010, 27, 564-579. [CrossRef]

49. Penven, P.; Echevin, V.; Pasapera, J.; Colas, F.; Tam, J. Average circulation, seasonal cycle, and mesoscale dynamics of the Peru Current System: A modeling approach. J. Geophys. Res. C Oceans 2005, 110, 1-21. [CrossRef]

50. Oey, L.Y. Loop current and deep eddies. J. Phys. Oceanogr. 2008, 38, 1426-1449. [CrossRef]

51. Dufau, C.; Orsztynowicz, M.; Dibarboure, G.; Morrow, R.; Le Traon, P.-Y. Mesoscale resolution capability of altimetry: Present and future. J. Geophys. Res. Oceans 2016, 121, 4910-4927. [CrossRef]

52. Pujol, M.I.; Faugère, Y.; Taburet, G.; Dupuy, S.; Pelloquin, C.; Ablain, M.; Picot, N. DUACS DT2014: The new multi-mission altimeter data set reprocessed over 20 years. Ocean Sci. 2016, 12, 1067-1090. [CrossRef]

53. Cai, S.; Su, J.; Gan, Z.; Liu, Q. The numerical study of the South China Sea upper circulation characteristics and its dynamic mechanism, in winter. Cont. Shelf Res. 2002, 22, 2247-2264. [CrossRef]

54. Bracco, A.; Pedlosky, J. Vortex generation by topography in locally unstable baroclinic flows. J. Phys. Oceanogr. 2003, 33, 207-219. [CrossRef]

55. Cushman-Roisin, B.; Beckers, J.-M. Introduction to Geophysical Fluid Dynamics: Physical and Numerical Aspects, 2nd ed.; Academic Press: Cambridge, MA, USA, 2011; ISBN 978-0-12-088759-0.

56. Castruccio, F.S.; Curchitser, E.N.; Kleypas, J.A. A model for quantifying oceanic transport and mesoscale variability in the Coral Triangle of the Indonesian/Philippines Archipelago. J. Geophys. Res. Oceans 2013, 118, 6123-6144. [CrossRef]

57. Liu, Q.; Feng, M.; Wang, D. ENSO-induced interannual variability in the southeastern South China Sea. J. Oceanogr. 2011, 67, 127-133. [CrossRef]

58. Zhu, Y.; Wang, L.; Wang, Y.; Xu, T.; Li, S.; Cao, G.; Wei, Z.; Qu, T. Stratified Circulation in the Banda Sea and Its Causal Mechanism. J. Geophys. Res. Oceans 2019, 124, 7030-7045. [CrossRef]

59. Xu, A.; Yu, F.; Nan, F. Study of subsurface eddy properties in northwestern Pacific Ocean based on an eddy-resolving OGCM. Ocean Dyn. 2019, 69, 463-474. [CrossRef] 